\section{$3 / 24-93 g 5(2$

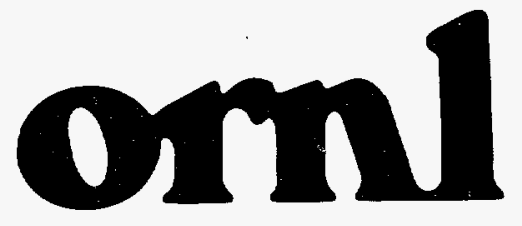

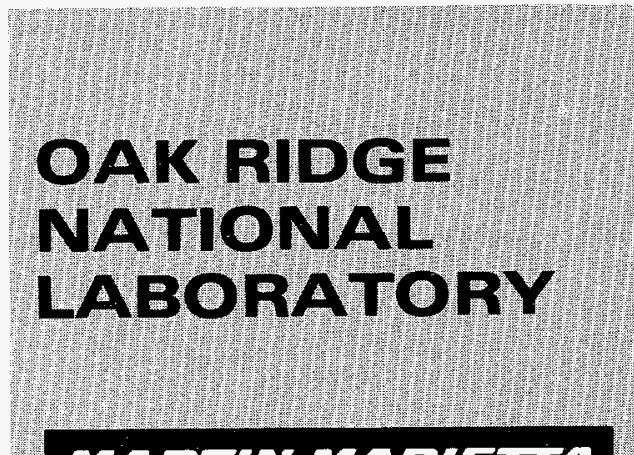

MALTIW MARUETRA

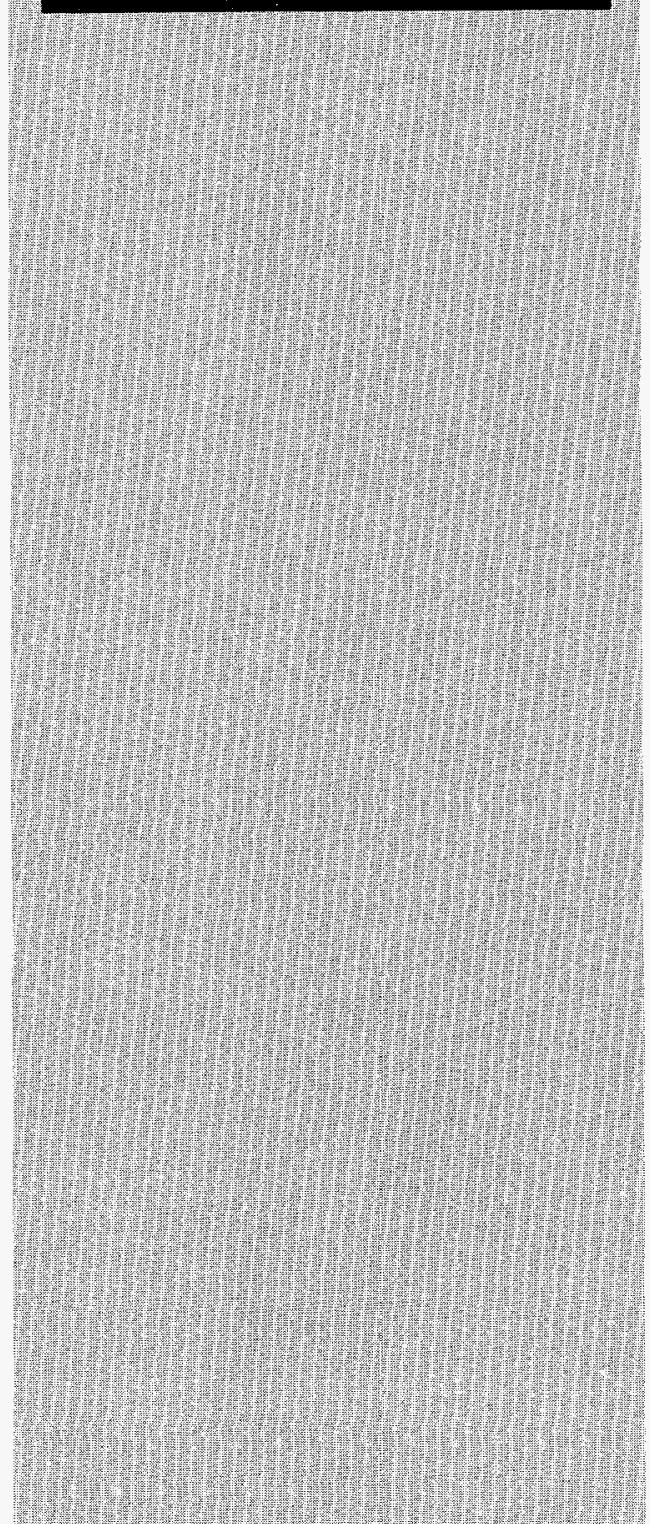

MANAGED BY

MARTIN MARIETTA ENERGY SYSTEMS, INC.

FOR THE UNITED STATES

DEPARTMENT OF ENERGY

\title{
Measurements for the JASPER Program Flux Monitor Experiment
}

\author{
F. J. Muckenthaler \\ R. R. Spencer \\ H. T. Hunter \\ J. L. Hull \\ A. Shono
}

\section{MASTER}


This report has been reproduced directly from the best available copy.

Available to DOE and DOE contractors from the Office of Scientific and Technical Information, P.O. Box 62, Oak Ridge, TN 37831; prices available from (615) 576-8401, FTS 626-8401.

This report was prepared as an account of work sponsored by an agency of the United States Government. Neither the United States Government nor any agency thereof, nor any of their employees, makes any warranty, express or implied, or assumes any legal liability or responsibility for the accuracy, completeness, or usefulness of any information, apparatus, product, or process disclosed, or represents that its use would not infringe privately owned rights. Reference herein to any specific commercial product, process, or service by trade name, trademark, manufacturer, or otherwise, does not necessarily constitute or imply its endorsement, recommendation, or favoring by the United States Government or any agency thereof. The views and opinions of authors expressed herein do not necessarily state or reflect those of the United States Government or any agency thereof. 
Engineering Physics and Mathematics Division

\title{
MEASUREMENTS FOR THE JASPER PROGRAM FLUX MONITOR EXPERIMENT
}

\author{
F. J. Muckenthaler \\ R. R. Spencer \\ H. T. Hunter \\ J. L. Hull* \\ A. Shono**
}

Date Published: February 1993

Oak Ridge National Laboratory

Oak Ridge, Tennessee 37831-6363

Prepared for the

U.S. DOE Office of

Liquid Metal Converter Reactor

"Research Reactors Division

* Japan Power Reactor and Nuclear Fuel Development Corporation

\section{DISCLAIMER}

This report was prepared as an account of work sponsored by an agency of the United States Government. Neither the United States Government nor any agency thereof, nor any of their employees, makes any warranty, express or implied, or assumes any legal liability or responsibility for the accuracy, completeness, or usefulness of any information, apparatus, product, or process disclosed, or represents that its use would not infringe privately owned rights. Reference herein to any specific commercial product, process, or service by trade name, trademark, manufacturer, or otherwise does not necessarily constitute or imply its endorsement, recommendation, or favoring by the United States Government or any agency thereof. The views and opinions of authors expressed herein do not necessarily state or reflect those of the United States Government or any agency thereof.

\author{
Prepared by the \\ OAK RIDGE NATIONAL LABORATORY \\ Oak Ridge, Tennessee 37831 \\ managed by \\ MARTIN MARIETTA ENERGY SYSTEMS, INC. \\ for the \\ U.S. Department of Energy \\ under contract DE-AC05-84OR21400
}




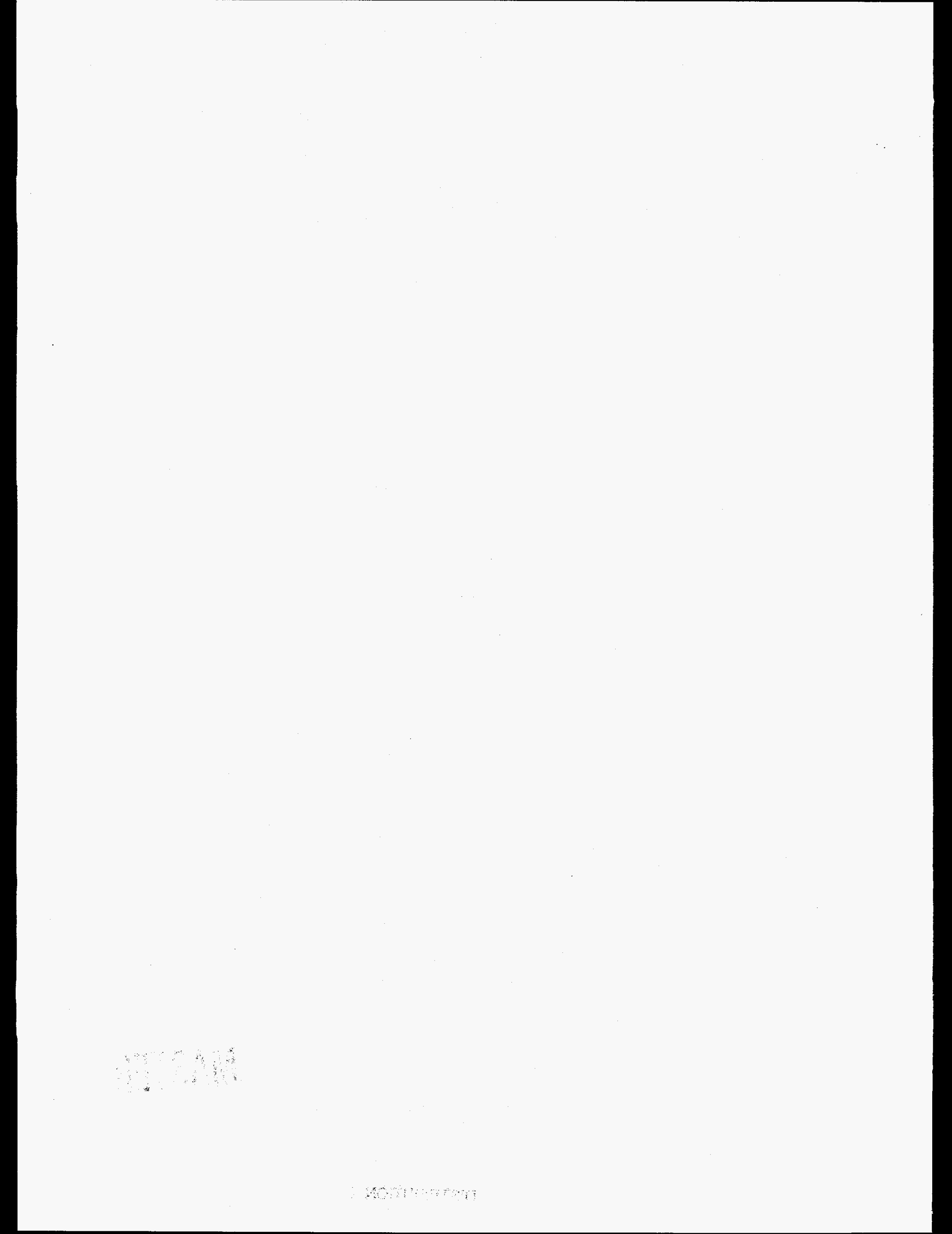


List of Tables $\ldots \ldots \ldots \ldots \ldots \ldots \ldots \ldots \ldots \ldots \ldots \ldots \ldots \ldots \ldots \ldots$

List of Figures $\ldots \ldots \ldots \ldots \ldots \ldots \ldots \ldots \ldots \ldots \ldots \ldots \ldots \ldots \ldots \ldots \ldots \ldots$

Abstract $\ldots \ldots \ldots \ldots \ldots \ldots \ldots \ldots \ldots \ldots \ldots \ldots \ldots \ldots \ldots \ldots \ldots$ ix

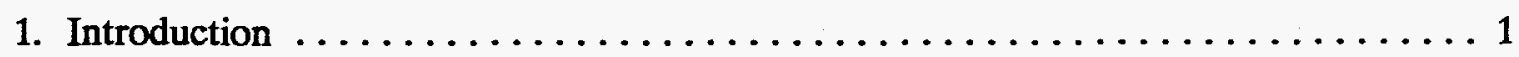

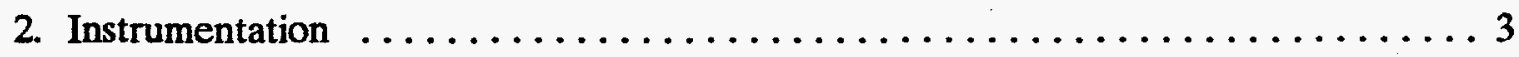

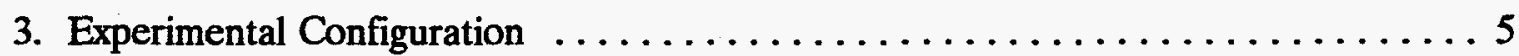

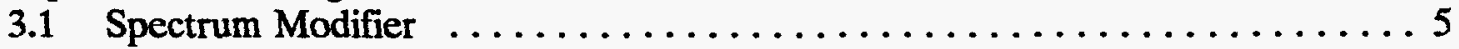

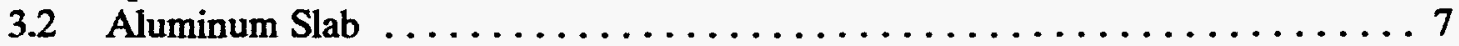

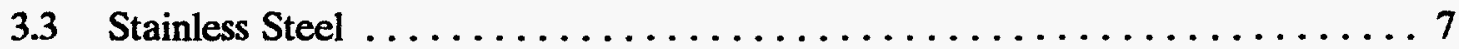

3.4 Lithiated Paraffin Shield $\ldots \ldots \ldots \ldots \ldots \ldots \ldots \ldots \ldots \ldots \ldots \ldots \ldots$

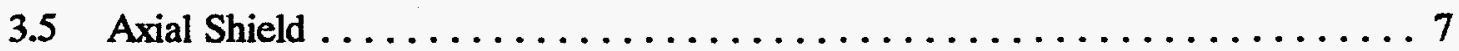

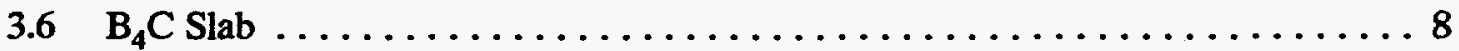

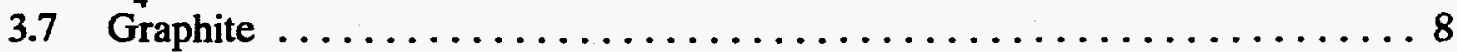

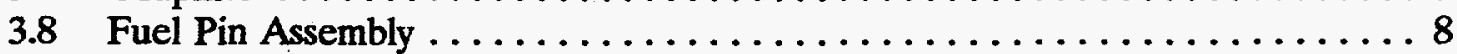

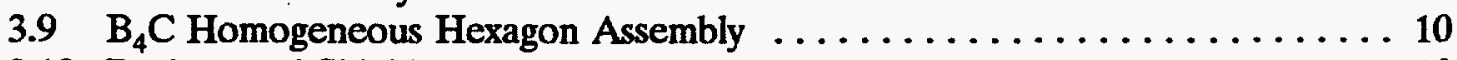

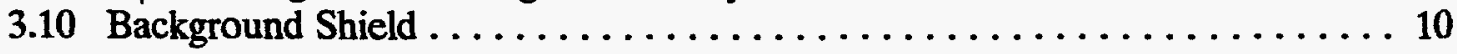

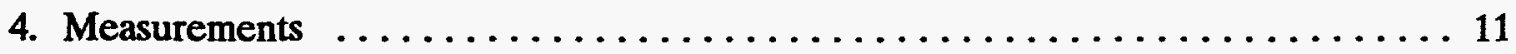

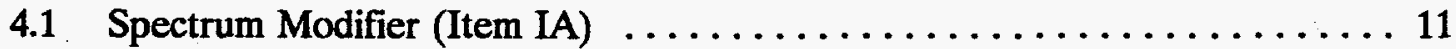

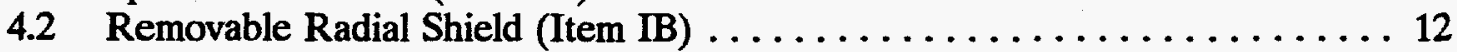

4.3 Removable Radial Shield + Axial Shield (Items IIA-F) . . . . . . . . 12

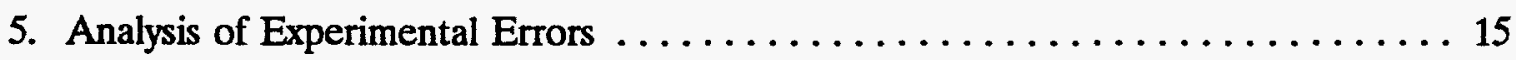

Acknowledgements $\ldots \ldots \ldots \ldots \ldots \ldots \ldots \ldots \ldots \ldots \ldots \ldots \ldots \ldots \ldots \ldots \ldots$

References $\ldots \ldots \ldots \ldots \ldots \ldots \ldots \ldots \ldots \ldots \ldots \ldots \ldots \ldots \ldots \ldots \ldots \ldots$

Appendix A. Experimental Program Plan for the JASPER Flux Monitor

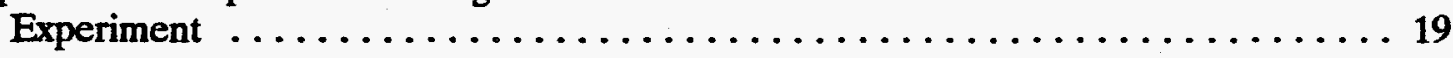

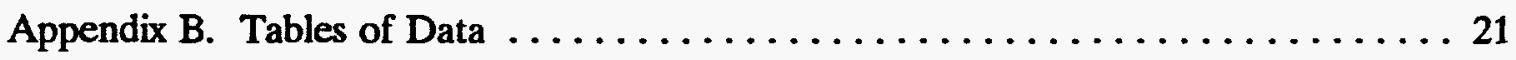

Appendix C. Figures $\ldots \ldots \ldots \ldots \ldots \ldots \ldots \ldots \ldots \ldots \ldots \ldots \ldots \ldots \ldots \ldots$ 


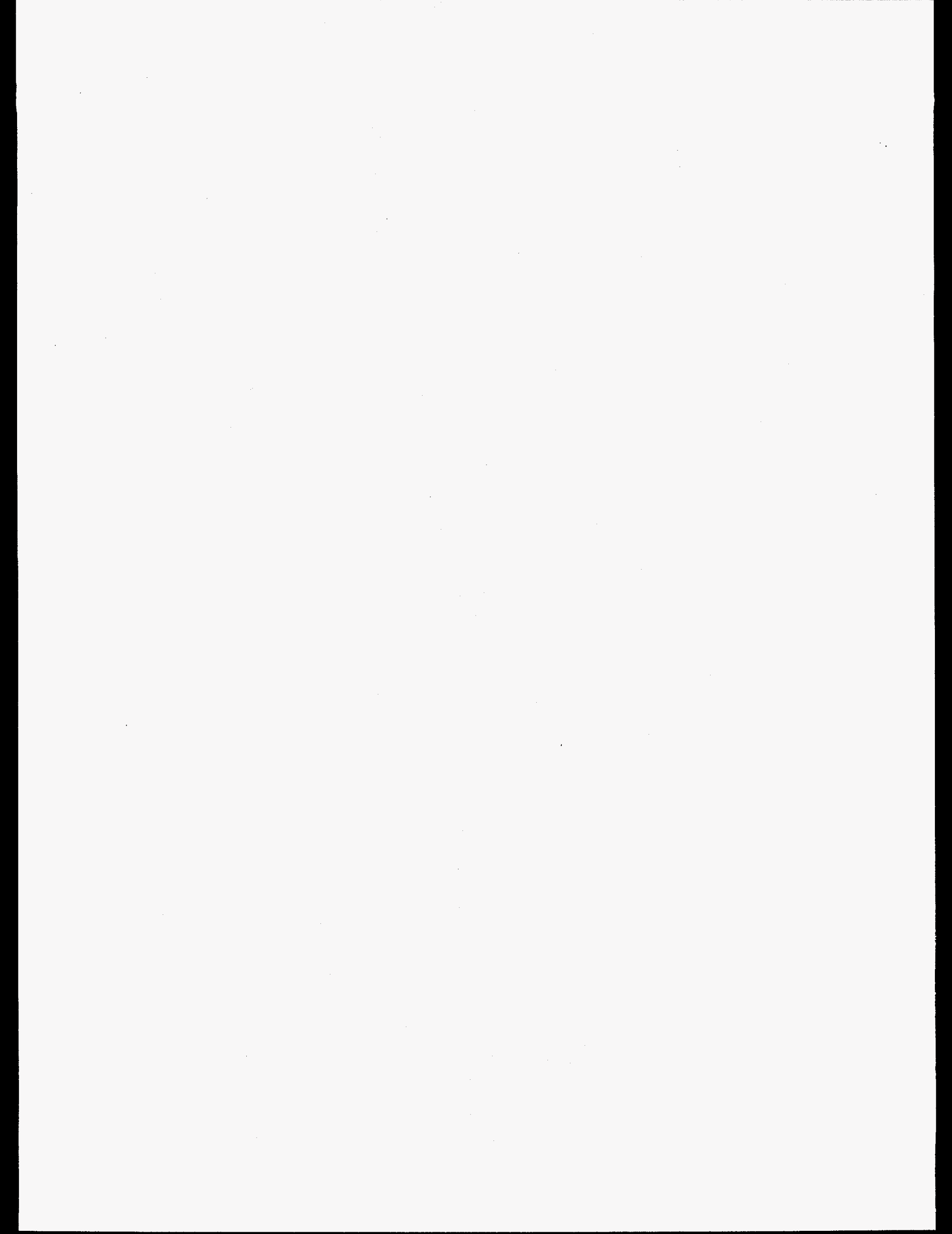




\section{DISCLAIMER}

Portions of this document may be illegible in electronic image products. Images are produced from the best available original document. 


\section{LIST OF TABLES}

Page

Table 1. Analysis of iron slabs $(\rho=7.86 \mathrm{~g} / \mathrm{cc})$ used in spectrum modifier $\ldots . .23$

Table 2. Analysis of aluminum slabs $(\rho=2.70 \mathrm{~g} / \mathrm{cc})$ used in spectrum modifier . 23

Table 3. Composition of boral slabs used in spectrum modifier . . . . . . . . 24

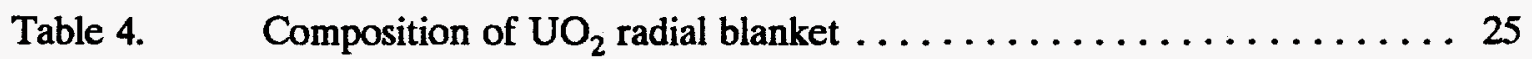

Table 5. Analysis of aluminum used in $\mathrm{UO}_{2}$ radial blanket cladding

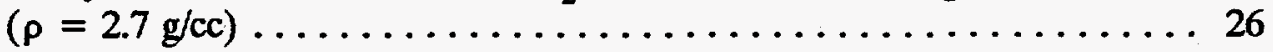

Table 6. Composition of lithiated-paraffin bricks $(\rho=1.15 \mathrm{~g} / \mathrm{cc}) \ldots \ldots 26$

Table 7. Analysis of $61-\mathrm{cm} \times 61-\mathrm{cm} \mathrm{x} 30.5-\mathrm{cm}(\rho=2.40 \mathrm{~g} / \mathrm{cc})$ concrete blocks used to surround configuration . . . . . . . . 27

Table 8. Analysis of type 304 stainless steel $(\rho=7.92 \mathrm{~g} / \mathrm{cc}) \ldots \ldots \ldots$

Table 9. Analysis of concrete in axial shield concrete slab $(\rho=2.40 \mathrm{~g} / \mathrm{cc}) \ldots . .29$

Table 10. Analysis of boron carbide used in shield mockups $\ldots \ldots \ldots \ldots$

Table 11. Analysis of graphite used in shield mockup $(\rho=1.62 \mathrm{~g} / \mathrm{cc}) \ldots \ldots 31$

Table 12. Analysis of $\mathrm{B}_{4} \mathrm{C}$ in hexagon assemblies $(\rho=1.41 \mathrm{~g} / \mathrm{cc}) \ldots \ldots . \ldots 32$

Table 13. Analysis of lead slabs $(p=11.35 \mathrm{~g} / \mathrm{cc}) \ldots \ldots \ldots \ldots \ldots \ldots \ldots \ldots$

Table 14. Bonner ball measurements on centerline at $30 \mathrm{~cm}$ behind a series of configurations

Table 15. Bonner ball measurements on centerline at $150 \mathrm{~cm}$ behind a

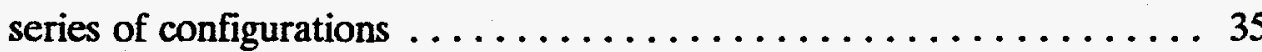

Table 16. Fast neutron fluxes $(>0.8 \mathrm{MeV})$ on centerline at $40 \mathrm{~cm}$ behind the stainless steel (Item IB): Run 7927A . . . . . . . . 37

Table 17. Neutron fluxes ( $50 \mathrm{keV}$ to $1.4 \mathrm{MeV}$ ) on centerline at $40 \mathrm{~cm}$ behind the stainless steel (Item IB) Runs 1598.C, 1598.B, 1598.A . . . . 38

Table 18. Bonner ball measurements on centerline at NE 213 location behind a series of configurations . . . . . . . . . . . . . . . . 39 
Table 19. 5-inch Bonner ball horizontal traverses through midplane at $30 \mathrm{~cm}$ behind mockup

Table 20. Bare and Cd-covered fission chamber horizontal traverses through midplane at $30 \mathrm{~cm}$ behind mockup . . . . . . . . . . 4

Table 21. Fast neutron fluxes $(>0.8 \mathrm{MeV})$ on centerline at $25 \mathrm{~cm}$ behind the lead slab (Item IIA) Run 7930A . . . . . . . . . . . . 42

Table 22. Neutron spectrum (50 keV to $1.4 \mathrm{MeV}$ ) on centerline at $25 \mathrm{~cm}$ behind the lead (Item IIA) Runs 1601.A, 1600.B, 1601.B . . . . . . . 43

Table 23. Bare and Cd-covered fission chamber horizontal traverses through midplane at $5 \mathrm{~cm}$ behind axial shield in the void 44

Table 24. 5-inch Bonner ball horizontal traverse through midplane behind axial shield in the void 


\section{LIST OF FIGURES}

Page

Figure 1. Schematic of the lithiated paraffin slabs with iris $\ldots \ldots \ldots \ldots \ldots$

Figure 2. Schematic of the superimposed lithiated paraffin slab iris upon the seven-hexagon arrangement in the axial shield ........50

Figure 3. Schematic of SM plus shield configuration for Items IA, IB, IIA, IIB, IIC . . . . . . . . . . . . . . . . 51

Figure 4. $\quad$ Schematic of radial blanket slab containing $\mathrm{UO}_{2} \ldots \ldots \ldots \ldots \ldots$

Figure 5. Schematic of the aluminum honeycomb within a concrete slab $\ldots \ldots 53$

Figure 6. Schematic of stainless steel containers used for boron carbide

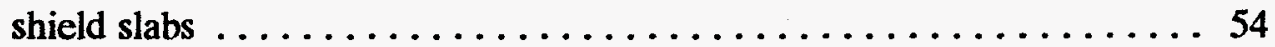

Figure 7. Isometric of the SPERT fuel rod containing Uranium-Dioxide

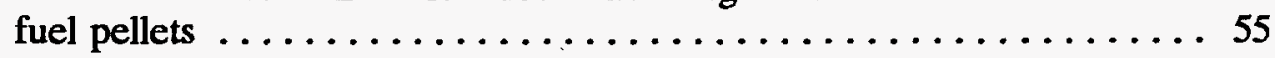

Figure 8. Schematic of thick IVFS mockup (slab \#1) $\quad$. $\ldots \ldots \ldots \ldots$

Figure 9. $\quad \mathrm{B}_{4} \mathrm{C}$ homogeneous-type assembly $\ldots \ldots \ldots \ldots \ldots \ldots \ldots$

Figure 10. Spectrum of high-energy neutrons $(>0.8 \mathrm{MeV})$ on centerline at $40 \mathrm{~cm}$ behind the stainless steel (Item IB) Run 7927A . . . . . . 58

Figure 11. Neutron spectrum ( $50 \mathrm{keV}$ to $1.4 \mathrm{MeV}$ ) on centerline at $40 \mathrm{~cm}$ behind the stainless steel (Item IB) Runs 1598.C, 1598.B, 1598.A . . . . 59

Figure 12. 5-inch Bonner ball horizontal traverses through midplane at $30 \mathrm{~cm}$ behind the mockup ....................60

Figure 13. Bare and Cd-covered fission chamber horizontal traverses through midplane at $30 \mathrm{~cm}$ behind the mockup ...........61

Figure 14. Schematic of SM plus shield configuration for Item IIA

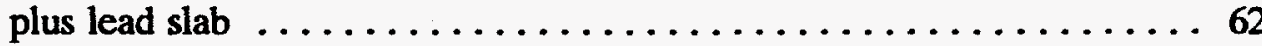

Figure 15. Spectrum of high-energy neutrons ( $>0.8 \mathrm{MeV})$ on centerline at $25 \mathrm{~cm}$ behind the lead slab (Item IIA) Run $7930 \mathrm{~A} \ldots \ldots \ldots 6 . \ldots 6$

Figure 16. Neutron spectrum ( $50 \mathrm{keV}$ to $1.4 \mathrm{MeV}$ ) on centerline at $25 \mathrm{~cm}$ behind the lead slab (Item IIA) Runs 1601.A, 1600.B, 1601.B 
Figure 17. Bare and Cd-covered fission chamber horizontal traverses through midplane at $5 \mathrm{~cm}$ behind the axial shield in the void (Item IIB, IIE)

Figure 18. 5-inch Bonner ball horizontal traverses through midplane in the void behind the axial shield

Figure 19. Schematic of SM plus shield configurations for Items IB, IIA, IID, IIE, IIF . 


\begin{abstract}
The Flux Monitor Experiment was conducted at the Oak Ridge National Laboratory (ORNL) Tower Shielding Facility (TSF) during the months of May and June 1992, as part of the continuing series of eight experiments planned for the JapaneseAmerican Shielding Program for Experimental Research (JASPER) program that was started in 1986. This series of experiments was designed to examine shielding concerns and radiation transport effects pertaining to in-vessel flux monitoring systems (FMS) in current reactor shield designs proposed for both the Advanced Liquid Metal Reactor (ALMR) design and the Japanese loop-type design. The program is a cooperative effort between the United States Department of Energy (U.S. DOE) and the Japanese Power Reactor and Nuclear Fuel Development Corporation (PNC).

The Tower Shielding Reactor II (TSR-II) neutron source was altered by the spectrum modifier (SM) used previously in the Axial Shield Experiment, and part of the Japanese Removable Radial Shield (RRS) before reaching the axial shield. In the axial shield were placed six homogeneous boron carbide $\left(\mathrm{B}_{4} \mathrm{C}\right)$ hexagons around a center hexagon of aluminum used to represent sodium. Shield designs to be studied were placed beyond the axial shield, each design forming a void directly behind the axial shield. Measurements were made in the void and behind each slab as successive slabs were added.
\end{abstract}




\section{INTRODUCTION}

This experiment is the seventh of eight experiments to be performed at the TSF that were jointly planned by ORNL, participant for the U.S. DOE, and the PNC. This phase of the overall program, called the Flux Monitor Experiment, was preceded by the Radial Shield Attenuation and Fission Gas Plenum Experiments completed in 1986-87, the Axial Shield Experiment completed in 1990, the In-Vessel Fuel Storage (IVFS) Experiment completed in 1991, the Intermediate Heat Exchanger (IHX) Activation and Gap Streaming Experiments completed earlier in 1992. All of the experiments performed have been planned jointly by ORNL and PNC representatives through a process of submitted proposals and mutual agreements.

The Flux Monitor Experiment was designed to examine the shielding concerns in the area of nuclear instrumentation systems (NIS) designed to monitor the neutron flux within the reactor vessel. The feasibility of an in-vessel location is affected by the core shielding design and, if the design includes a sodium window to enhance the neutron flux at the monitor, the ability to further shield the instrumentation if needed.

In this experiment, a SM of iron, aluminum, boral, and "radial blankets" followed by a RRS of stainless steel were used to provide a near-core neutron spectrum incident on the modified axial shield. This shield contained six of the homogeneous $\mathrm{B}_{4} \mathrm{C}$ hexagons used in the previous axial shield experiment surrounding a central hexagon of sodium represented by aluminum. Slab arrangements followed the axial shield to provide the mockups studied. The mockups studied and the measurements made are described in the program plan in Appendix A. 


\section{INSTRUMENTATION}

The TSF Bonner ball detection system consists of a series of detectors (polyethylene balls), each of which measures an integral of the neutron flux weighted by the energy-dependent response function for that ball. The detection device of a Bonner ball consists of a 5.1-cm-diameter spherical proportional counter filled with boron trifluoride $\left(\mathrm{BF}_{3}\right)$ gas $\left({ }^{10} \mathrm{~B} / \mathrm{B}\right.$ concentration $\left.=0.96\right)$ to a pressure of 0.5 atmospheres. In order to cover a range of neutron energies, the counter is used bare, covered with cadmium, or enclosed in various thicknesses of polyethylene shells surrounded by cadmium, each detector being identified by the diameter of its shell. Bonner ball experimental results are predicted analytically by folding a calculated neutron spectrum with the Bonner ball response functions determined by R. E. Maerker et al. ${ }^{1}$ and C. E. Burgart et al. ${ }^{2}$

An NE 213 liquid scintillator spectrometer covered the neutron spectral region from about $800 \mathrm{keV}$ to $15 \mathrm{MeV}$. This device makes use of pulse-shape discrimination (PSD) to distinguish neutrons from gamma-ray pulses. Pulse-height data obtained with the spectrometer were unfolded with the FERD $\operatorname{code}^{3}$ to yield absolute neutron energy spectra.

Spherical proton-recoil counters, filled with hydrogen to pressures of 1,3 , and 10 atmospheres, covered the neutron energy range from about $50 \mathrm{keV}$ to $1 \mathrm{MeV}$. Pulseheight data from the counters were unfolded with the SPEC- 4 code, ${ }^{4}$ which makes use of the unfolded NE 213 neutron spectrum to correct for effects of higher-energy neutrons.

A fission chamber was added to the list of instruments available at the TSF for measurement of the neutron transmission through shield mockups. The sensitive area consists of $29 \mathrm{mg}$ of Uranium enriched to $93.15 \%{ }^{235} \mathrm{U}(27 \mathrm{mg}$ ) plated on a $0.0254-\mathrm{cm}$ thick nickel plate, covering a circular area of $31 \mathrm{~cm}^{2}$. The detector is identical in physical features to that of the fission chambers used to monitor the reactor power on a daily basis and serves as a replacement. The fission chamber was used in this experiment to provide a direct measure of the thermal neutron fission rate. Its response to thermal neutrons was compared to that of gold $\mathrm{(Au}$ ) foils when exposed to a reactor flux. This calibration gave a thermal neutron sensitivity of $6.37 \times 10^{-1}$ neutrons $/ \mathrm{cm}^{2} / \mathrm{sec}$ per count $/$ minute difference between the bare and cadmium-covered fission chamber readings. 
The measurements for each detector were referenced to the reactor power (watts) using the data from two fission chambers positioned along the reactor centerline as a basis. The response of these chambers as a function of reactor power level was established previously through several calorimetric measurements of the heat generated in the reactor during a temperature equilibrium condition (heat power run). 


\section{EXPERIMENTAL CONFIGURATION}

The experimental program called for measurements behind mockups that were representative of the shields at locations of the flux monitor in-vessel nuclear instrumentation system (NIS) beyond the radial shield in the Japanese loop-type design and above the core in the U.S. ALMR design. Representation of the shield for both of these locations was satisfied through the use of a spectrum modifier of iron, aluminum, boral, and "radial blankets" followed by the RRS of stainless steel and the axial shield containing the central hexagon of aluminum (sodium) surrounded by the six hexagons of $\mathrm{B}_{4} \mathrm{C}$. In between the stainless steel and the axial shield was placed a 10.16-cm-thick slab of lithiated paraffin bricks containing a central void (see Figure 1) that essentially matched the dimensions and shape of the $\mathrm{B}_{4} \mathrm{C}$ around the outer six hexagons in the axial shield as shown in Figure 2. The slabs, and their arrangement in the mockups to be studied, followed the axial shield. The neutron source was a collimated TSR-II beam.

Measurements were made behind the mockups and in the voids as called for in the program plan.

It should be noted that the thicknesses of the material mentioned in the program plan are nominal, the actual thicknesses of each of the slabs are given in the left corner of the slabs as displayed in the figures in Appendix $\mathrm{C}$. The values refer to measurements along the beam centerline, that is, at the center of the slab. The distance from the reactor centerline to the detector side of each slab in the schematics was measured along the centerline of the mockups.

\subsection{SPECTRUM MODIFIER}

A pre-analysis indicated that nominally $10 \mathrm{~cm}$ of iron, $10 \mathrm{~cm}$ of aluminum, $2.5 \mathrm{~cm}$ of boral, followed by $20.3 \mathrm{~cm}$ of "radial blanket" would provide the desired incident neutron spectrum. In the mockup of the modifier, see Figure 3, the iron component consisted of two slabs, 5.20 and $5.13 \mathrm{~cm}$ thick, both being $152.4 \mathrm{~cm}$ on an edge. The aluminum thickness consisted of three slabs totalling $9.12 \mathrm{~cm}$. The boral consisted of two slabs for a total thickness of $2.54 \mathrm{~cm}$. The slabs used throughout this experiment except for the IVFS vessel, were $152.4 \mathrm{~cm}$ on an edge. Compositions of the iron, aluminum, and boral are given in Tables 1, 2, and 3 respectively (Note: all tables are included in 
Appendix B).

The uranium $\left(\mathrm{UO}_{2}\right)$ slabs described as "radial blankets" had been fabricated for use in earlier experiments performed as part of the Liquid Metal Fast Breeder Reactor (LMFBR) program at the TSF. The slabs contain natural $\mathrm{UO}_{2}$ pellets, $1.40 \mathrm{~cm}$ outer diameter (O.D.) enclosed in aluminum cylinders having an O.D. of $1.524 \mathrm{~cm}$. The space between the aluminum cylinder and the $\mathrm{UO}_{2}$ pellets, $0.00508-0.01016 \mathrm{~cm}$, is filled with argon. The cylinders are stacked side-by-side vertically in a triangular pitch of $1.608 \mathrm{~cm}$. The space between the aluminum cylinders is filled with sodium. This arrangement of $\mathrm{UO}_{2}$ pellets is enclosed in an iron vessel having an overall thickness of $11.05 \mathrm{~cm}$ and a length of $152.4 \mathrm{~cm}$ on an edge as seen in the schematic in Figure 4.

Each of the radial blanket slabs contain 522 rods amounting to $64.6 \%$ of the volume of the slab. The rods stand vertically in alternate rows of 74 and 75 pins each. The $\mathrm{UO}_{2}$ density is $10.28 \mathrm{~g} / \mathrm{cc}$ (94\% of theoretical). The volume fraction of the aluminum cladding is $11.2 \%$ and that for the sodium is $23.3 \%$, leaving a void (argon) volume fraction between the pellet and the aluminum cylinder of $1 \%$. The stacked length of the pellets in each of the rods is approximately $121.9 \mathrm{~cm}$. These rods were built by the Numes Corporation in 1962 to conform, in general, to the then Atomic Energy Commission (AEC)/Reactor Development Technology (RDT) design standards for the Fast Flux Test Facility (FFTF). Analyses of the $\mathrm{UO}_{2}$ and aluminum are given in Tables 4 and 5 respectively.

The sides, top, and bottom of the spectrum modifier and all the succeeding slabs, except the axial shield, were surrounded by lithiated paraffin bricks, a thickness that was not constant. Along the sides it was $20.3 \mathrm{~cm}$. The mockup slabs were supported directly by a slab, $30.5 \mathrm{~cm}$ thick, containing both a $20.3-\mathrm{cm}$ layer of lithiated paraffin and a $10.2-\mathrm{cm}$ layer of concrete, with the lithiated paraffin layer adjacent to the mockup slabs. Due to the stainless steel pieces at the top of each slab that were necessary to secure each slab in the mockup, the thickness of lithiated paraffin in that area varied from 20 to $30.5 \mathrm{~cm}$. In all cases, the lithiated paraffin was surrounded by a minimum of $61 \mathrm{~cm}$ of concrete, with additional concrete placed around the mockup to reduce the background reaching the detector. The compositions of the lithiated paraffin and the concrete are given in Tables 6 and 7. 


\subsection{ALUMINUM SLAB}

The 1.27-cm-thick aluminum slab used in the RRS was placed immediately behind the radial blanket to mockup a sodium flow area between the SM and the radial shield. That slai was of the same aluminum (type 6061) used in the SM described earlier.

\subsection{STAINLESS STEEL}

The three stainless steel slabs that mocked up the RRS in this experiment were $5.15,5.15$ and $5.27 \mathrm{~cm}$ thick, and extended $152.4 \mathrm{~cm}$ on an edge. They are typical of type 304 stainless steel, whose chemical composition can be found in Table 8 . The stainless steel pieces used in the homogeneous $B_{4} C$ subassemblies are of the same type 304 .

\subsection{LITHIATED PARAFFIN SHIELD}

A lithiated paraffin brick slab, $10.16 \mathrm{~cm}$ thick, was placed between the stainless steel slabs and the axial shield to enhance the neutron flux penetrating the hexagons with respect to the flux scattered from the concrete around the $\mathrm{B}_{4} \mathrm{C}$ hexagons into the hexagon assemblies and reaching the detector. The slab, $152.4 \mathrm{~cm}$ on an edge, contained a void at the center shaped in the form of a cross, whose dimensions closely matched the perimeter of the $\mathrm{B}_{4} \mathrm{C}$ collar surrounding the seven hexagon assemblies in the axial shield. The shape and dimensions of the void were given previously in Figure 1. The composition of the lithiated paraffin is given in Table 6.

\subsection{AXIAL SHIELD}

The mockup for the Flux Monitor Experiment used the same 45-cm-thick axial shield fabricated for the previous Axial Shield Experiment performed in 1990.5 The shield was composed of a combination of seven subassemblies briefly described as a central hexagon surrounded by six others. For this experiment, the central assembly contained aluminum to represent a sodium window to enhance the flux monitor response. The slabs in the SM and RRS and the hexagons in the axial shield arrangement provide a good representation of the U.S. ALMR shield designs and the loop-type NIS arrangement for the Japanese. 
The six subassemblies surrounding the central assembly were filled with a homogeneous $\mathrm{B}_{4} \mathrm{C}$ arrangement studied earlier in the Axial Shield Experiment. To support these assemblies in a horizontal plane, an aluminum honeycomb structure, shown in Figure 5, was secured in a concrete slab. The honeycomb itself represented a path for sodium flow between subassemblies in a typical LMR axial shield design.

Between the honeycomb and the surrounding concrete slab was a layer of $\mathrm{B}_{4} \mathrm{C}$ whose width varied as seen in Figure 2 . The $\mathrm{B}_{4} \mathrm{C}$ had an average density of $1.3 \mathrm{~g} / \mathrm{cc}$. The $\mathrm{B}_{4} \mathrm{C}$ was covered on both ends of the honeycomb with an $0.81-\mathrm{cm}$-thick aluminum plate, making the total length of the shield in that region about $46.6 \mathrm{~cm}$, while the mesh length was only $45 \mathrm{~cm}$. The concrete slab was $304.8 \mathrm{~cm}$ wide, $213.4 \mathrm{~cm}$ high, and $45 \mathrm{~cm}$ thick. The analysis of the concrete in the slab is contained in Table 9.

\section{6 $\mathrm{B}_{4} \mathrm{C}$ SLAB}

The $\mathrm{B}_{4} \mathrm{C}$ slab used in this experiment consisted of a stainless steel can $152.4 \mathrm{~cm}$ on an edge, filled with 120 grit $\mathrm{B}_{4} \mathrm{C}$ powder. The container is identified by $1 \mathrm{~W}$ in Figure 6 . The thickness of the slab, including the stainless steel faces, was $16.95 \mathrm{~cm}$ as measured along the centerline. Spacer pins were used to maintain constant thickness within the thin walls. The density of the $\mathrm{B}_{4} \mathrm{C}$ was found to be $1.42 \mathrm{~g} / \mathrm{cc}$. An analysis of the $\mathrm{B}_{4} \mathrm{C}$ powder is given in Table 10. The amount of boron nitride (BN) as a component in this slab was not established; however, previous analysis (see ORNL/TM-11839) indicated there were several percent present in similar $\mathrm{B}_{4} \mathrm{C}$ samples.

\subsection{GRAPHITE}

A combination of graphite pieces, $30.48-\mathrm{cm}$ and $121.9-\mathrm{cm}-$ long and $10.16 \mathrm{~cm}$ on a side, were stacked to form a slab $152.4 \mathrm{~cm}$ on an edge and $20.3 \mathrm{~cm}$ thick. The pieces were precisely machined to provide good surface-to-surface contact and eliminate possible voids for neutron streaming. An analysis and density are given in Table 11.

\subsection{FUEL PIN ASSEMBLY}

A total of $\mathbf{1 2 0 0}$ pins were secured from the University of Florida for the JASPER experiments. The pins were originally fabricated for use at the U.S. AEC's National 
Reactor Testing Station near Idaho Falls, Idaho, for Special Power Excursion Reactor tests, hence the notation SPERT fuel. Each of the rods consists of slightly enriched (4.81\%) sintered $\mathrm{UO}_{2}$ pellets encased in a 304 stainless steel tube and capped at both ends with stainless steel. In each rod there exists an aluminum oxide $\left(\mathrm{Al}_{2} \mathrm{O}_{3}\right)$ insulator between the $\mathrm{UO}_{2}$ pellets and the stainless steel caps at each end. Gas caps for fuel expansion are provided at the upper end of the rod and around the pellets. A spring is located atop the fuel pellets to keep the pellets in place. The characteristics of a typical SPERT fuel rod may be seen, along with the schematic, in Figure 7. As is noted in the figure, the active fuel length is $91.44 \mathrm{~cm}$, with an overall length of the fuel rod, ends included, of $106.05 \mathrm{~cm}$. The pellets are $1.067 \mathrm{~cm}$ in diameter and are clad in $1.184 \mathrm{~cm}$ O.D. stainless steel tubing with walls $0.051 \mathrm{~cm}$ thick. The $\mathrm{UO}_{2}$ fuel pellet density is 10.08 $\mathrm{g} / \mathrm{cc}$ and the ${ }^{235} \mathrm{U}$ in each rod amounts to 35.2 grams. Each of the pins is numbered to enhance record keeping. What was not noted in the schematic is that each of the pins has a weld bead at the top and bottom of the rod where the end caps join the tubing containing the fuel. This weld is slightly larger in diameter $(1.2 \mathrm{~cm})$ than the stainless steel tubing $(1.184 \mathrm{~cm})$ and this larger diameter required some last minute changes in the fabrication of the vessels.

For this experiment 1148 pins were packed in the "thick" vessel to provide a maximum neutron multiplication. The vessel was $94.96 \mathrm{~cm}$ wide, $18.31 \mathrm{~cm}$ thick, $111.3 \mathrm{~cm}$ high, and fabricated of stainless steel as shown in Figure 8. The pins were stacked vertically in the vessel, resulting in eight rows of 77 pins each alternating with seven rows of 76 pins, each spaced on a triangular pitch of $1.20 \mathrm{~cm}$ based on the diameter of the welds. Because the diameter of the welds exceeded the diameter of the rods there existed a small void between the pins.

When the vessel was placed in the mockup it was necessary to place additional support beneath it to center the vessel on the reactor beam centerline. This was accomplished with $20.3 \mathrm{~cm}$ of lithiated paraffin. Likewise, since the width of the vessel was smaller than the typical configuration slab $(97 \mathrm{~cm}$ compared to $152.4 \mathrm{~cm}$ ), the extra space between the vessel and concrete on each side was filled with additional lithiated paraffin bricks. 


\section{9 $\mathrm{B}_{4} \mathrm{C}$ HOMOGENEOUS HEXAGON ASSEMBLY}

The $\mathrm{B}_{4} \mathrm{C}$ homogeneous assembly was composed of alternating pieces of $\mathrm{B}_{4} \mathrm{C}$ and stainless steel, a schematic of which is shown in Figure 9. The $\mathrm{B}_{4} \mathrm{C}$ was contained in an aluminum vessel, the internal depth of the $\mathrm{B}_{4} \mathrm{C}$ powder being $7.77 \mathrm{~cm}$. The width of the $B_{4} C$ was $14.73 \mathrm{~cm}$ from inside flat surface to inside flat surface with a wall thickness of $0.627 \mathrm{~cm}$, making the outside dimensions of the container $15.98 \mathrm{~cm}$. Each end plate thickness covering the $\mathrm{B}_{4} \mathrm{C}$ was $1.123 \mathrm{~cm}$. The density of the $\mathrm{B}_{4} \mathrm{C}$ powder (120 grit) was $1.41 \mathrm{~g} / \mathrm{cc}$. An analysis of the powder is given in Table 12. The thickness of the stainless steel pieces was $1.25 \mathrm{~cm}$. When the hexagon was placed in the configuration, an aluminum-enclosed $\mathrm{B}_{4} \mathrm{C}$-loaded container was placed nearest the reactor, followed by alternating pieces of stainless and aluminum clad $\mathrm{B}_{4} \mathrm{C}$.

\subsection{BACKGROUND SHIELD}

It has been the custom in the past to obtain background measurements along with foreground when the detectors were located at sufficient distances behind the mockups where neutron contributions to the detector from areas other than the mockup itself might not be negligible. For the background measurements, a container of lithiated paraffin bricks, $91.4 \mathrm{~cm}$ by $91.4 \mathrm{~cm}$ by $40.6 \mathrm{~cm}$ thick, was usually placed between the detector and mockup slabs in such a manner that contributions directly to the detector from just the mockup would be greatly reduced. This procedure was followed for the Bonner ball measurements at $150 \mathrm{~cm}$. For the background measurements behind the axial shield when no slabs were present, the same $152.4-\mathrm{cm}$-square area for a typical slab was assumed to exist and the shadow shield was positioned as though a slab were present. 


\section{MEASUREMENTS}

The mockups studied in this experiment were preceded by the combination of a spectrum modifier followed by an RRS and an axial shield consisting of an aluminum hexagon surrounded by six hexagons of homogeneous $\mathrm{B}_{4} \mathrm{C}$ subassemblies. The aluminum hexagon represented a sodium window that was included to enhance the neutron flux reaching the flux monitor. The axial shield had been used in the previous Axial Shield Experiment and analysis of those results had indicated a probability that the concrete around the hexagon mockup was scattering neutrons back through the hexagons and reaching the detector, resulting in a higher reading for the neutrons penetrating the shield. In an effort to minimize that effect, a slab of lithiated paraffin, $10.2 \mathrm{~cm}$ thick, and containing a void that matched the outline of the $\mathrm{B}_{4} \mathrm{C}$ border around the hexagons, was placed between the RRS and the axial shield as shown in Figure 3. The design of the lithiated paraffin slab is shown in Figure 1. The SM, RRS, lithiated paraffin slab, and the axial shield subassemblies remained fixed throughout the experiment.

A lead slab was required behind the mockup in Item IIA to reduce the gamma ray flux to neutron flux ratio to an acceptable level for obtaining the fast neutron spectrum with the NE 213 scintillator. The scintillator was placed at $25 \mathrm{~cm}$ behind the lead for the measurement, eliminating the need for a background measurement. It was not necessary, however, to use lead for the spectral measurements in Item IB. An analysis of the lead slab is given in Table 13.

Throughout this report, the words configuration, item, and mockup are used interchangeably when referring to the contents of the program plan.

\subsection{SPECTRUM MODIFIER (ITEM IA)}

The SM was used previously in the JASPER experiment, ${ }^{6}$ so the measurements behind it in this experiment were limited to just the Bonner balls on centerline at $\mathbf{3 0}$ and $150 \mathrm{~cm}$. A schematic of the modifier is given in Figure 3.

Results from the measurements with the bare, cadmium-covered, 3-, 5-, 8-, and $10-$ inch Bonner balls at $30 \mathrm{~cm}$ are given in Table 14 and those at $150 \mathrm{~cm}$, both foreground and background, can be found in Table 15. 


\subsection{REMOVABLE RADIAL SHIELD (TTEM M)}

The RRS, consisting of a $1.26 \mathrm{~cm}$ slab of aluminum followed by three slabs of stainless steel, $5.15,5.15$, and $5.27 \mathrm{~cm}$ thick, was placed in the mockup, followed by the lithiated paraffin slab described earlier in the report (see Section 3.4).

Results from the fast neutron spectrum obtained with the NE 213 scintillator at 40 $\mathrm{cm}$ behind the stainless steel slabs are listed in Table 16 and plotted in Figure 10. The lower energy region of the neutron spectrum obtained with the 1-, 3-, and 10-atmosphere hydrogen-proton recoil detectors is listed in Table 17 and plotted in Figure 11.

Measurements with the 3-, 5-, and 10-inch Bonner balls at the NE 213 location are given in Table 18.

Centerline measurements were made with the bare, cadmium-covered, 3-, 5-, 8-, and 10-inch Bonner balls at 30 and $150 \mathrm{~cm}$ and these results are given in Tables 14 and 15 respectively. A traverse through the horizontal midplane with the 5-inch Bonner ball was made at $30 \mathrm{~cm}$ behind the stainless steel and these data are listed in Table 19 and plotted in Figure 12. The traverse was repeated with the fission chamber, bare and cadmiumcovered, and these results are recorded in Table 20 and plotted in Figure 13.

\subsection{REMOVABLE RADIAL SHIELD + AXIAL SHIELD (ITEMS IIA-F)}

The axial shield containing the central aluminum subassembly surrounded by the six homogeneous $\mathrm{B}_{4} \mathrm{C}$ hexagons was placed in the mockup so that the center of the aluminum hexagon coincided with the reactor beam centerline and the center of the iris in the lithiated paraffin slab. A single lead slab, $3.81 \mathrm{~cm}$ thick, was placed behind the axial shield during measurement of the neutron spectrum as shown in Figure 14. Results from the fast part of the spectrum measured with the NE 213 at $25 \mathrm{~cm}$ behind the lead can be found in Table 21 and plotted in Figure 15. Data obtained with the hydrogen-filled proton-recoil counters are given in Table 22 and plotted in Figure 16. Results from measurements with the 3-, 5-, and 10-in Bonner balls at the spectrometer location are given in Table 18. Centerline measurements were made at 30 and $150 \mathrm{~cm}$ behind the axial shield with the six Bonner balls after the lead slab was removed and these values are listed in Tables 14 and 15. A radial traverse at $30 \mathrm{~cm}$ behind the mockup was made with the 5-in Bonner ball and these data points are in Table 19 and plotted in Figure 12. Similar 
traverses were made with the fission chamber bare and cadmium covered and these data are contained in Table 20 and plotted in Figure 13.

A $34.92-\mathrm{cm}$-deep void was created directly behind the axial shield when the 16.96-cm-thick $\mathrm{B}_{4} \mathrm{C}$ slab was placed in the mockup to give Item IIB, shown in Figure 3. This depth was chosen to provide enough space for movement of the fission chamber within the void. The sensitive area of the fission chamber was located $5 \mathrm{~cm}$ from the axial shield during the traverse. The detector was run bare and cadmium covered and these results are recorded in Table 23 and plotted in Figure 17. A similar traverse was made with the 5-inch Bonner ball at $17 \mathrm{~cm}$ behind the axial shield in the void and these data points are part of Table 24 and plotted in Figure 18. A radial traverse was repeated at 30 $\mathrm{cm}$ behind the $\mathrm{B}_{4} \mathrm{C}$ slab with the 5-inch Bonner ball and the result is listed in Table 19 and plotted in Figure 12. Centerline measurements were made with the bare, cadmium covered, 3-, 5-, 8-, and 10-inch Bonner balls at 30 and $150 \mathrm{~cm}$ behind the $\mathrm{B}_{4} \mathrm{C}$ and these results are given in Tables 14 and 15.

The addition of $20.3 \mathrm{~cm}$ of graphite created the mockup for Item IIC (Figure 3). The measurements were limited to those with the series of Bonner balls at 30 and $150 \mathrm{~cm}$ on centerline behind the mockup. These data are included in Tables 14 and 15 respectively.

The $\mathrm{B}_{4} \mathrm{C}$ and graphite were removed from the mockup and a new 35.2-cm-void space was created behind the axial shield with the addition of the "thickn vessel of fuel pins to give Item IID in the program, see the schematic in Figure 19. Since the vessel width and length are somewhat smaller than for a typical slab, the difference was made up with lithiated paraffin bricks to center the vessel on the beam centerline. Bonner ball measurements were made on the centerline at 30 and $150 \mathrm{~cm}$ behind the IVFS. These results are given in Tables 14 and 15 respectively. A radial traverse was made with the 5-inch Bonner ball at $30 \mathrm{~cm}$ behind the mockup and the data are contained in Table 19 and plotted in Figure 12.

Fifteen $\mathrm{cm}$ of $\mathrm{B}_{4} \mathrm{C}$ were placed behind the IVFS vessel to give the mockup shown in Figure 19 for Item IIE. Measurements were made in the void and behind the mockups. Results from the bare and cadmium covered fission chamber radial traverses within the void at $5 \mathrm{~cm}$ behind the axial shield are given in Table 23 and plotted in Figure 17. A similar traverse with the 5 -inch Bonner ball at $16 \mathrm{~cm}$ behind the axial shield gave the data 
reported in Table 24 and plotted in Figure 18. The Bonner ball data obtained from measurements behind the mockup at 30 and $150 \mathrm{~cm}$ along the centerline are recorded in Tables 14 and 15. Data from a radial traverse at $30 \mathrm{~cm}$ behind the mockup are part of Table 19 and are plotted in Figure 12.

The final mockup, Item IIF, formed by the addition of $20.3 \mathrm{~cm}$ of graphite behind the $\mathrm{B}_{4} \mathrm{C}$ slab in Item IIE, is shown in Figure 19. Only centerline measurements with the Bonner balls were made behind this mockup, and the results from measurements at 30 and $150 \mathrm{~cm}$ are given in Tables 14 and 15. 


\section{ANALYSIS OF EXPERIMENTAL ERRORS}

The errors associated with the measurements are due to a number of uncertainties: (1) the sizes of the gaps between slabs, unavoidably introduced in mocking up the configurations; (2) the positioning of the detectors; (3) the detector count rate statistics and calibrations; (4) the reactor power determinations; and (5) the effects of the exposure of the configurations to the weather. Of these, the uncertainty due to the weather is the least understood and could not be simply estimated. The uncertainty lies in the amount of moisture collecting between the slabs and in the lithiated paraffin surrounding them. During this experiment, however, the mockups were covered with a plastic tarpaulin in order to limit the amount of moisture reaching the slabs. Thus, for this experiment, the effect of the weather was assumed to be negligible.

The TSR-II power level for each measurement was determined from the output of two fission chambers located in the reactor shield along the midplane of the reactor. The response of these chambers to the reactor source was monitored prior to the experiment through the use of gold foils and this ratio, detector response to gold foil results, agreed within about $5 \%$ with a history of earlier such comparisons. These detectors were calibrated on a daily basis using a californium $\left({ }^{252} \mathrm{Cf}\right)$ source, with the calibration values lying within about a $6 \%$ spread ( $\pm 3 \%$ of an average value). During any one detector traverse in a given day, the variation in the reactor power indicated by the monitor outputs was at most only $3 \%$; however, during the several months the experiment was being performed, the monitors indicated a spread in any one power level of about $\pm 5 \%$. Thus, the uncertainty in the reactor power determination was assumed to be $\pm 5 \%$.

Count-rate statistics are expressed in a manner specific to each detector. For the NE 213 measurements, counting statistics and unfolding errors are included in the unfolding of the pulse-height spectra using the FERD code, with the resulting flux expressed in terms of lower and upper limits that represent a $68 \%$ confidence interval. Similar errors are expressed in the tabular data for the hydrogen measurements unfolded using SPEC4. Neither of the spectra, NE 213 or hydrogen counter, reflects the error in determining the reactor power since this error is not included in the unfolding program. This, as seen above, could be as much as $\pm 5 \%$.

The Bonner ball detector was calibrated on a daily basis using californium $\left({ }^{252} \mathrm{Cf}\right)$ as a source, with the resulting count rates, normalized to the source strength. This ratio 
normally falls within about $\pm 3 \%$ of an average value that has been obtained over a period of years. Experimental data is then obtained through the use of a traversing mechanism that moves the detector with respect to the mockup while maintaining reactor power. Physical limitations of the traversing mechanism allows movement of the Bonner ball several millimeters to either side of a straight line as it travels from point to point. For the measurements perpendicular to the configuration centerline at $30 \mathrm{~cm}$ behind the configurations, such variations in the detector position could correspond to changes in the count rate of about $\bullet 2 \%$. For the measurements on centerline beyond the $30 \mathrm{~cm}$ point, the error in positioning several millimeters either side of the selected location would lie well within the statistics of the measurement.

The fission chamber used throughout this experiment as a companion detector to the Bonner balls was calibrated on a daily basis using the thermal neutron flux generated by placement of the ${ }^{252} \mathrm{Cf}$ in a jug of lucite. The resulting count rates fell within about ${ }_{ \pm} 5 \%$ of an average value obtained throughout the experiment. Movement of the fission chamber was similar to that of the Bonner ball described earlier and the procedure in determining the possible errors with this detector follow that described for the Bonner balls.

Thus, rather than calculate the probable errors for each measurement in a series of measurements we preferred, in general, to quote a value for the error in the measurements for a given experiment. Thus, assuming the estimated upper limit for all the errors noted above, the errors assigned to both the Bonner ball and the fission chamber measurements should lie within about $\pm 10 \%$. 


\section{ACKNOWLEDGEMENTS}

The authors are deeply indebted to D. T. Ingersoll and J. V. Pace, III, of ORNL's Engineering Physics and Mathematics Division, to P. B. Hemmig of DOE/Washington, and to the JASPER working group from Japan for their participation and assistance in formulating the Experimental Program Plan. A deep gratitude is expressed to the TSR-II operating crew of the Research Reactors Division and TSF assigned members of the Instrumentation and Controls Division for not only maintaining a viable source but for experimental help when needed. Appreciation is expressed to E. R. Specht, Rockwell International, W. H. Harless, General Electric Company, R. K. Disney, WestinghouseARD, W. L. Bunch, Westinghouse-Hanford for timely suggestions. Special thanks go to G. A. Marvin and S. A. Raby for their efforts in editing and preparing this report.

\section{REFERENCES}

1. R. E. Maerker et al., Calibration of the Bonner Ball Neutron Detectors Used at the Tower Shielding Facility, ORNL/TM-3465 (June 1971).

2. C. E. Burgart and M. B. Emmett, Monte Carlo Calculations of the Response Functions of Bonner Ball Neutron Detectors, ORNL/TM-3739 (April 1972).

3. B. W. Rust, D. T. Ingersoll, and W. R. Burrus, $A$ User's Manual for the FERDO and FERD Unfolding Codes, ORNL/TM-8720 (September 1983).

4. J. O. Johnson and D. T. Ingersoll, User's Guide for the Revised SPEC-4 Neutron Spectrum Unfolding Code, ORNL/TM-7384 (August 1980).

5. F. J. Muckenthaler et al., Measurements for the JASPER Program Axial Shield Experiment, ORNL-TM-11839 (August 1990).

6. F. J. Muckenthaler et al., Measurements for the JASPER Program In-Vessel Fuel Storage Experiment, ORNL/TM-11989 (January 1992). 



\section{APPENDIX A \\ EXPERIMENTAL PROGRAM PLAN FOR THE JASPER FLUX MONITOR EXPERIMENT}

I. Spectrum Modifier + RRS Mockup

A. $\quad \mathrm{SM}(10 \mathrm{~cm} \mathrm{Fe}+9 \mathrm{~cm} \mathrm{Al}+2.5 \mathrm{~cm}$ boral $+20 \mathrm{~cm}$ radial blanket $)+$ concrete on sides of modifier

1. 3-, 5-, 8-, and 10-in Bonner ball measurements on centerline:

a. $\quad 30 \mathrm{~cm}$ behind spectrum modifier

b. $\quad 150 \mathrm{~cm}$ behind spectrum modifier (foreground and background)

B. IA $+1.3 \mathrm{~cm} \mathrm{Al}+15 \mathrm{~cm} \mathrm{SS}+10 \mathrm{~cm} \mathrm{Li} \mathrm{Par} \mathrm{with} \mathrm{seven} \mathrm{hexagonal} \mathrm{iris}$

1. NE 213/Benjamin spectrometer measurements on centerline as close as feasible behind shield mockup

2. 3-, 5-, and 10-in Bonner ball measurements on centerline at NE 213 location

3. Bare, cadmium (Cd)-covered, 3-, 5-, 8-, and 10-in Bonner ball measurements on centerline:

a. $\quad 30 \mathrm{~cm}$ behind shield mockup

b. $\quad 150 \mathrm{~cm}$ behind shield mockup (foreground and background)

4. $\mathrm{U}^{235}$ fission chamber horizontal traverse at $30 \mathrm{~cm}$ behind mockup (bare and Cd-covered)

5. 5-in Bonner ball horizontal traverse at $30 \mathrm{~cm}$ behind shield mockup

II. RRS + Axial Shield

A. $\quad \mathrm{SM}+1.3 \mathrm{~cm} \mathrm{Al}+15 \mathrm{~cm} \mathrm{SS}$ plus axial shield with Aluminum hexagonal center surrounded by $\mathrm{B}_{4} \mathrm{C}$ homogeneous hexagons. Precede axial shield with $10 \mathrm{~cm}$ lithiated paraffin covering face of SM with 7 hexagonal holes matching axial shield.

1. NE 213/Benjamin spectrometer measurements on centerline as close as feasible behind shield mockup

2. 3-, 5-, and 10-in Bonner ball measurements on centerline at NE 213 location

3. Bare, Cd-covered, 3-, 5-, 8-, and 10-in Bonner ball measurements on centerline:

a. $\quad 30 \mathrm{~cm}$ behind shield mockup

b. $\quad 150 \mathrm{~cm}$ behind shield mockup (foreground and background)

4. $\mathrm{U}^{235}$ fission chamber horizontal traverse at $30 \mathrm{~cm}$ behind mockup (bare and Cd-covered)

5. 5-in Bonner ball horizontal traverse at $\mathbf{3 0} \mathrm{cm}$ behind shield mockup 
B. II. A $+30 \mathrm{~cm}$ void $+15 \mathrm{~cm} \mathrm{~B} 4$

1. Bare, Cd-covered, 3-, 5-, 8-, and 10-in Bonner ball measurements on centerline:

a. $\quad 30 \mathrm{~cm}$ behind shield mockup

b. $\quad 150 \mathrm{~cm}$ behind shield mockup (foreground and background)

2. $\quad$-in Bonner ball horizontal traverse in middle of void

3. $\quad 5$-in Bonner ball horizontal traverse at $30 \mathrm{~cm}$ behind shield mockup

4. $\quad{ }^{235} \mathrm{U}$ fission chamber horizontal traverse at $5 \mathrm{~cm}$ in the void (bare and Cd-covered)

C. II.A $+30 \mathrm{~cm}$ void $+15 \mathrm{~cm} \mathrm{~B} 4+20 \mathrm{~cm}$ graphite

1. Bare, Cd-covered, 3-, 5-, 8-, and 10-in Bonner ball measurements on centerline:

a. $\quad 30 \mathrm{~cm}$ behind shield mockup

b. $\quad 150 \mathrm{~cm}$ behind shield mockup (foreground and background)

D. II.A $+30 \mathrm{~cm}$ void + thick IVFS mockup

1. Bare, Cd-covered, 3-, 5-, 8-, and 10-in Bonner ball measurements on centerline:

a. $\quad 30 \mathrm{~cm}$ behind shield mockup

b. $\quad 150 \mathrm{~cm}$ behind shield mockup (foreground and background)

2. $\quad 5$-in Bonner ball horizontal traverse at $30 \mathrm{~cm}$ behind shield mockup

E. II.A $+30 \mathrm{~cm}$ void + thick IVFS mockup $+15 \mathrm{~cm} \mathrm{~B} \mathrm{C}_{4} \mathrm{C}$

1. Bare, Cd-covered, 3-, 5-, 8-, and 10-in Bonner ball measurements on centerline:

a. $\quad 30 \mathrm{~cm}$ behind shield mockup

b. $\quad 150 \mathrm{~cm}$ behind shield mockup (foreground and background)

2. $\quad 5$-in Bonner ball horizontal traverse in middle of void

3. 5-in Bonner ball horizontal traverse at $30 \mathrm{~cm}$ behind shield mockup

4. $\quad{ }^{235} \mathrm{U}$ fission chamber horizontal traverse at $5 \mathrm{~cm}$ in the void (bare and Cd-covered)

F. II.A $+30 \mathrm{~cm}$ void + thick IVFS $+15 \mathrm{~cm} \mathrm{~B}$ C $+20 \mathrm{~cm}$ graphite

1. 3-, 5-, 8-, and 10-in Bonner ball measurements on centerline:

a. $\quad 30 \mathrm{~cm}$ behind shield mockup

b. $\quad 150 \mathrm{~cm}$ behind shield mockup (foreground and background) 
APPENDIX B

TABLES OF DATA 

Table 1. Analysis of iron slabs $(p=7.86 \mathrm{~g} / \mathrm{cc}$ ) used in spectrum modifier

\begin{tabular}{lc}
\hline Element & wt \% \\
\hline & \\
$\mathrm{Fe}$ & 98.4 \\
$\mathrm{C}$ & .25 \\
$\mathrm{Cr}$ & .15 \\
$\mathrm{Cu}$ & .03 \\
$\mathrm{Mn}$ & 1.0 \\
$\mathrm{Mo}$ & .02 \\
$\mathrm{Ni}$ & .05 \\
$\mathrm{Si}$ & .25 \\
\hline
\end{tabular}

Table 2. Analysis of aluminum slabs $(\rho=2.70 \mathrm{~g} / \mathrm{cc}$ ) used in spectrum modifier

\begin{tabular}{lcr} 
Element & wt \% & ppm \\
\hline & & \\
$\mathrm{Al}$ & 97.5 & \\
$\mathrm{Cr}$ & .22 & \\
$\mathrm{Cu}$ & .23 & \\
$\mathrm{Fe}$ & .47 & \\
$\mathrm{Mg}$ & .86 & \\
$\mathrm{Mn}$ & .01 & \\
$\mathrm{Si}$ & .63 & \\
$\mathrm{Ti}$ & .042 & \\
$\mathrm{Zn}$ & .07 & \\
$\mathrm{Li}$ & & 3 \\
$\mathrm{Ni}$ & & 50 \\
$\mathrm{Sn}$ & & $<10$ \\
$\mathrm{~V}$ & & 150 \\
& & \\
\hline
\end{tabular}


Table 3. Composition of boral slabs used in spectrum modifier

\begin{tabular}{clcc}
\hline & \multicolumn{2}{c}{$\left(\mathrm{B}_{4} \mathrm{C}-40-43\right.$ vol \% in $\mathrm{B}_{4} \mathrm{C}-\mathrm{Al}$ mixture) } \\
\cline { 2 - 4 } Component & $\begin{array}{l}\text { Density } \\
(\mathrm{g} / \mathrm{cc})\end{array}$ & $\begin{array}{c}\text { Elemental } \\
\text { Composition } \\
(\text { wt \%) }\end{array}$ & $\begin{array}{c}\text { With } \\
\text { Al Cladding } \\
\text { (wt \%) }\end{array}$ \\
\hline & & & \\
$\mathrm{B}_{4} \mathrm{C}$ & 2.3 & & $\sim 75$ \\
$\mathrm{Al}$ & 2.70 & 65 & $\sim 19.6$ \\
$\mathrm{~B}$ & & 27.5 & $\sim 5.4$ \\
$\mathrm{C}$ & & 7.5 & \\
\hline
\end{tabular}


Table 4. Composition of $\mathrm{UO}_{2}$ radial blanket

\begin{tabular}{lcc}
\hline Component & vol \% & $\begin{array}{c}\text { Density } \\
\text { (g/cc) }\end{array}$ \\
\hline & & \\
$\mathrm{UO}_{2}$ (pellets) & 64.6 & 10.28 \\
$\mathrm{Al}(8001)$ & 11.2 & 2.8 \\
$\mathrm{Na}$ & 23.2 & 0.92 \\
Void & 1.0 & --- \\
\hline
\end{tabular}

$\mathrm{U}$ content 88.18 wt $\%$ of $\mathrm{UO}_{2}$

\begin{tabular}{llll}
\hline \multicolumn{4}{c}{ Isotope \% } \\
\hline${ }^{234} \mathrm{U}$ & .0053 & ${ }^{236} \mathrm{U}$ &.- \\
${ }^{235} \mathrm{U}$ & .713 & ${ }^{238} \mathrm{U}$ & 99.28 \\
\hline
\end{tabular}

Metallic Impurities in $\mathrm{UO}_{2}(\mathrm{ppm})^{*}$

\begin{tabular}{lllrlrr}
\hline & & & & & \\
$\mathrm{Al}$ & $<20$ & $\mathrm{Cu}$ & 1 & $\mathrm{Na}$ & $<20$ \\
$\mathrm{~B}$ & $<1$ & $\mathrm{~F}$ & $<2$ & $\mathrm{Ni}$ & $<10$ \\
$\mathrm{Be}$ & $<2$ & $\mathrm{Fe}$ & $<20$ & $\mathrm{~Pb}$ & $<4$ \\
$\mathrm{Bi}$ & $<2$ & $\mathrm{H}_{2} \mathrm{O}$ & 2.1 & $\mathrm{Si}$ & $<20$ \\
$\mathrm{C}$ & $<10$ & $\mathrm{Li}$ & $<1$ & $\mathrm{Sn}$ & $<2$ \\
$\mathrm{Ca}$ & $<20$ & $\mathrm{Mg}$ & $<10$ & $\mathrm{Ta}$ & $<25$ \\
$\mathrm{Cd}$ & $<0.5$ & $\mathrm{Mn}$ & $<4$ & $\mathrm{Tu}$ & $<4$ \\
$\mathrm{Cl}$ & $<3.3$ & $\mathrm{Mo}$ & $<10$ & $\mathrm{~W}$ & $<25$ \\
$\mathrm{Co}$ & $<2$ & $\mathrm{~N}$ & 54 & $\mathrm{Zr}$ & $<25$ \\
$\mathrm{Cr}$ & $<10$ & & & & \\
& & & &
\end{tabular}


Table 5. Analysis of aluminum used in $\mathrm{UO}_{2}$ radial blanket cladding $(\rho=27 \mathrm{~g} / \mathrm{cc})$

\begin{tabular}{ccc}
\hline & & \\
Element & wt \% & ppm \\
\hline & & \\
$\mathrm{Al}$ & $\mathrm{Major}$ & \\
$\mathrm{Fe}$ & .59 & \\
$\mathrm{Ni}$ & 1.13 & \\
$\mathrm{~B}$ & & $<6$ \\
$\mathrm{Be}$ & $<20$ \\
$\mathrm{Cd}$ & $<20$ \\
$\mathrm{Co}$ & $<20$ \\
$\mathrm{Cr}$ & $<6$ \\
$\mathrm{Cu}$ & 52.9 \\
$\mathrm{Li}$ & & 6 \\
$\mathrm{Mg}$ & & 3.04 \\
$\mathrm{Mn}$ & 11.2 \\
$\mathrm{Mo}$ & $<6$ \\
$\mathrm{~Pb}$ & $<20$ \\
$\mathrm{Si}$ & 27.5 \\
$\mathrm{Sn}$ & $<60$ \\
$\mathrm{~T}$ & $<2000$ \\
$\mathrm{Ti}$ & 65.5 \\
$\mathrm{~V}$ & 44.2 \\
$\mathrm{~W}$ & $<60$ \\
$\mathrm{Zr}$ & $<20$ \\
& \\
\hline
\end{tabular}

Table 6. Composition of lithiated-paraffin bricks $(\rho=1.15 \mathrm{~g} / \mathrm{cc})$

\begin{tabular}{ll}
\hline Component & wt \% \\
\hline $\mathrm{C}_{\mathrm{n}} \mathrm{H}_{2 \mathrm{n}+2}$ & 60 \\
$\mathrm{Li}_{2} \mathrm{CO}_{3}$ & 40 \\
\hline
\end{tabular}


Table 7. Analysis of $61-\mathrm{cm} \times 61-\mathrm{cm} \times 30.5-\mathrm{cm}(\rho=240 \mathrm{~g} / \mathrm{cc})$ concrete blocks used to surround configuration

\begin{tabular}{cccc}
\hline Component & wt\% & Component & wt\% \\
\hline $\mathrm{CO}_{3}$ & 41.9 & $\mathrm{Al}_{2} \mathrm{O}_{3}$ & 2.2 \\
$\mathrm{Ca}$ & 27.4 & $\mathrm{Fe}_{2} \mathrm{O}_{3}$ & .60 \\
$\mathrm{SiO}_{2}$ & 18.1 & $\mathrm{SO}_{3}$ & .32 \\
$\mathrm{H}_{2} \mathrm{O}$ & 4.0 & $\mathrm{P}_{2} \mathrm{O}_{5}$ & .035 \\
$\mathrm{Mg}$ & 3.66 & $\mathrm{~K}$ & .30 \\
$\mathrm{O}_{2}$ & 1.4 & & \\
\hline
\end{tabular}


Table 8. Analysis of type 304 stainless steel $(\rho=7.92 \mathrm{~g} / \mathrm{cc})$

\begin{tabular}{lcc}
\hline \multirow{2}{*}{ Element } & \multicolumn{2}{c}{ wt\% } \\
& Lower & Upper \\
\hline $\mathrm{Fe}$ & 68.1 & -71.2 \\
$\mathrm{Cr}$ & 18.0 & -19.1 \\
$\mathrm{Ni}$ & 8.8 & -9.8 \\
$\mathrm{Mn}$ & 1.04 & -1.65 \\
$\mathrm{Si}$ & 0.33 & -0.65 \\
$\mathrm{C}$ & 0.024 & -0.085 \\
$\mathrm{O}_{2}$ & 0.013 & -0.021 \\
$\mathrm{P}$ & & 0.028 \\
$\mathrm{~S}$ & & 0.022 \\
$\mathrm{Mo}$ & & 0.30 \\
$\mathrm{Cu}$ & & 0.26 \\
$\mathrm{Co}$ & & 0.10 \\
& & \\
\hline
\end{tabular}


Table 9. Analysis of concrete in axial shield concrete slab $(\rho=240 \mathrm{~g} / \mathrm{cc})$

\begin{tabular}{lc}
\hline \multicolumn{1}{c}{ Element } & $\begin{array}{c}\text { Axial shield } \\
\text { concrete } \\
(\%)\end{array}$ \\
\hline Free $\mathrm{H}_{2} \mathrm{O}$ & .97 \\
$\mathrm{Bound} \mathrm{H}_{2} \mathrm{O}$ & 2.44 \\
$\mathrm{LOI}^{*}$ & 35.25 \\
$\mathrm{SiO}_{2}$ & 9.41 \\
$\mathrm{Fe}_{2} \mathrm{O}_{3}$ & .94 \\
$\mathrm{Al}_{2} \mathrm{O}_{3}$ & 1.57 \\
$\mathrm{CaO}$ & 36.96 \\
$\mathrm{MgO}$ & 13.2 \\
$\mathrm{Na}_{2} \mathrm{O}$ & .022 \\
$\mathrm{~K}_{2} \mathrm{O}$ & .53 \\
$\mathrm{SO}_{3}$ & .16 \\
$\mathrm{P}_{2} \mathrm{O}_{5}$ & .10 \\
$\mathrm{CO}_{3}$ & 43.9 \\
\hline${ }^{\circ} \mathrm{LOI}\left(\mathrm{Lost}\right.$ on Ignition) includes the free and bound $\mathrm{H}_{2} \mathrm{O}$ \\
and SO . To obtain correct wt\% for the materials, \\
multiply $\mathrm{CO}_{3}$ value by .7334 to get $\mathrm{CO}_{2}$ and when \\
summed the LOI values should not be included. \\
\end{tabular}


Table 10. Analysis of boron carbide used in shield mockups

\begin{tabular}{|c|c|c|}
\hline Element & wt\% & ppm \\
\hline B & 76.7 & \\
\hline $\mathrm{C}$ & 19.52 & \\
\hline $\mathrm{Al}$ & & 50 \\
\hline $\mathrm{Ca}$ & & 800 \\
\hline $\mathrm{Cl}$ & & 10 \\
\hline Co & & $<1$ \\
\hline $\mathrm{Cr}$ & & 2 \\
\hline $\mathrm{Cu}$ & & $<1$ \\
\hline $\mathrm{Fe}$ & & 600 \\
\hline $\mathrm{Mg}$ & & 25 \\
\hline $\mathbf{M n}$ & & 10 \\
\hline $\mathrm{Na}$ & & 1 \\
\hline $\mathbf{P}$ & & 2 \\
\hline $\mathbf{S}$ & & 5 \\
\hline $\mathbf{S i}$ & & 50 \\
\hline $\mathrm{Ti}$ & & 225 \\
\hline
\end{tabular}


Table 11. Analysis of graphite used in shield mockup ( $\rho=1.62 \mathrm{~g} / \mathrm{cc}$ )

\begin{tabular}{cccccc}
\hline \multicolumn{5}{c}{ Metallic Impurities in Carbon (ppm) } \\
\hline $\mathrm{Ag}$ & $<0.5$ & $\mathrm{Ge}$ & $<5$ & $\mathrm{Sb}$ & $<10$ \\
$\mathrm{Al}$ & 12.5 & $\mathrm{Hg}$ & $<10$ & $\mathrm{Si}$ & 100 \\
$\mathrm{~B}$ & 1.5 & $\mathrm{In}$ & $<10$ & $\mathrm{Sn}$ & $<10$ \\
$\mathrm{Ba}$ & $<5$ & $\mathrm{~K}$ & $<100$ & $\mathrm{Sr}$ & $<10$ \\
$\mathrm{Be}$ & $<0.5$ & $\mathrm{Li}$ & $<2$ & $\mathrm{Ta}$ & $<10$ \\
$\mathrm{Bi}$ & $<10$ & $\mathrm{Mg}$ & 7.5 & $\mathrm{Te}$ & $<25$ \\
$\mathrm{Ca}$ & 150 & $\mathrm{Mn}$ & $<1$ & $\mathrm{Ti}$ & 30 \\
$\mathrm{Cd}$ & $<25$ & $\mathrm{Mo}$ & $<5$ & $\mathrm{~V}$ & 100 \\
$\mathrm{Co}$ & $<10$ & $\mathrm{Na}$ & $<5$ & $\mathrm{~W}$ & $<5$ \\
$\mathrm{Cr}$ & $<10$ & $\mathrm{Nb}$ & $<5$ & $\mathrm{Zn}$ & 10 \\
$\mathrm{Cu}$ & 7.5 & $\mathrm{Ni}$ & $<10$ & $\mathrm{Zr}$ & $<5$ \\
$\mathrm{Fe}$ & 50 & $\mathrm{~Pb}$ & $<5$ & & \\
$\mathrm{Ga}$ & $<10$ & $\mathrm{Rb}$ & $<5$ & &. \\
\hline
\end{tabular}


Table 12 Analysis of $\mathrm{B}_{4} \mathrm{C}$ in hexagon assemblies $(\rho=1.41 \mathrm{~g} / \mathrm{cc})$

\begin{tabular}{|c|c|c|c|}
\hline Sample \# & \% Boron & \% Carbon & $\%$ Boron Nitride \\
\hline 1 & 78.2 & 20.0 & 1.8 \\
\hline 2 & 78.2 & 20.4 & 1.6 \\
\hline 3 & 78.2 & 20.0 & 1.8 \\
\hline Element & Sample \#1 & Sample \# $2^{*}$ & Sample \# ${ }^{*}$ \\
\hline Al & 5 & 10 & 3 \\
\hline $\mathrm{Ca}$ & 5 & 5 & 30 \\
\hline Co & $<1$ & $<1$ & $<1$ \\
\hline $\mathrm{Cr}$ & 1 & 3 & 3 \\
\hline $\mathrm{Cl}$ & 3 & 5 & 3 \\
\hline $\mathrm{Cu}$ & 3 & 3 & 3 \\
\hline $\mathrm{Fe}$ & 10 & 50 & 50 \\
\hline $\mathrm{Mg}$ & $<5$ & 10 & 5 \\
\hline Mn & 1 & 3 & 5 \\
\hline $\mathrm{Na}$ & 5 & 10 & 30 \\
\hline $\mathbf{P}$ & 3 & 3 & 3 \\
\hline Sc & 3 & 3 & 3 \\
\hline $\mathrm{Si}$ & $<20$ & $<20$ & $<20$ \\
\hline $\mathrm{Ti}$ & 3 & 3 & 10 \\
\hline
\end{tabular}

"Parts per million 
Table 13. Analysis of lead slabs $(\rho=11.35 \mathrm{~g} / \mathrm{cc})$

\begin{tabular}{ccc}
\hline Element & wt\% & PPM \\
\hline $\mathrm{Pb}$ & 99.9 & \\
$\mathrm{Al}$ & & $<3$ \\
$\mathrm{Ag}$ & & 30 \\
$\mathrm{~B}$ & & $<1$ \\
$\mathrm{Ca}$ & 1 \\
$\mathrm{Cr}$ & 10 \\
$\mathrm{Cu}$ & 800 \\
$\mathrm{Fe}$ & 1 \\
$\mathrm{Li}$ & 20 \\
$\mathrm{Mg}$ & $<3$ \\
$\mathrm{Mn}$ & 5 \\
$\mathrm{Na}$ & & 1 \\
$\mathrm{Ni}$ & 30 \\
$\mathrm{P}$ & 5 \\
$\mathrm{Si}$ & $<3$ \\
$\mathrm{Sn}$ & & 30 \\
\hline
\end{tabular}


Table 14. Bonner ball measurements on centerline at $30 \mathrm{~cm}$ behind a series of configurations

\begin{tabular}{|c|c|c|c|c|c|c|}
\hline \multirow[b]{2}{*}{ Configuration $^{a}$} & \multicolumn{6}{|c|}{ Count rate $\left(s^{-1} W^{-1}\right)$} \\
\hline & Bare Detector & $\begin{array}{c}\text { Cd-Covered } \\
\text { Detector } \\
\end{array}$ & $\begin{array}{c}\text { 3-in-Diam } \\
\text { Ball } \\
\end{array}$ & $\begin{array}{c}\text { 5-in-Diam } \\
\text { Ball } \\
\end{array}$ & $\begin{array}{c}\text { 8-in-Diam } \\
\text { Ball } \\
\end{array}$ & $\begin{array}{c}\text { 10-in-Diam } \\
\text { Ball } \\
\end{array}$ \\
\hline IA & $3.22(1)^{b}$ & $1.00(1)$ & $6.60(2)$ & $3.14(3)$ & $2.24(3)$ & $1.22(3)$ \\
\hline IB & $2.58(1)$ & $9.17(0)$ & $2.17(2)$ & $7.98(2)$ & $5.09(2)$ & $2.38(2)$ \\
\hline IIA & $1.26(-1)$ & $2.01(-2)$ & $1.08(0)$ & $4.18(0)$ & $2.31(0)$ & $9.44(-1)$ \\
\hline IIB & $7.49(-4)$ & $8.85(-5)$ & $5.83(-3)$ & $3.18(-2)$ & $2.42(-2)$ & $1.34(-2)$ \\
\hline IIC & $1.81(-3)$ & $2.66(-4)$ & $3.60(-3)$ & $8.23(-3)$ & $4.26(-3)$ & $2.13(-3)$ \\
\hline IID & $1.58(-3)$ & $6.27(-4)$ & $3.81(-2)$ & $2.11(-1)$ & $1.62(-1)$ & $9.25(-2)$ \\
\hline IIE & $5.23(-4)$ & $3.79(-5)$ & $2.16(-3)$ & $1.58(-2)$ & $1.59(-2)$ & $1.01(-2)$ \\
\hline IIF & $1.01(-3)$ & $1.30(-4)$ & $1.87(-3)$ & $5.08(-3)$ & $3.08(-3)$ & $1.64(-3)$ \\
\hline
\end{tabular}

${ }^{a}$ See experimental program plan in Appendix A for description of configurations.

${ }^{b}$ Read: $3.22 \times 10^{1}$. 
Table 15. Bonner ball measurements on centerline at $150 \mathrm{~cm}$ behind a series of configurations

\begin{tabular}{|c|c|c|c|c|c|c|c|}
\hline \multirow[b]{3}{*}{ Configuration $^{a}$} & \multicolumn{7}{|c|}{ Count rate $\left(s^{-1} W^{-1}\right)$} \\
\hline & \multicolumn{3}{|c|}{ Bare Detector } & \multicolumn{2}{|c|}{ Cd-Covered Detector } & \multicolumn{2}{|c|}{ 3-in-Diam Ball } \\
\hline & Foreground $^{b}$ & Background $^{c}$ & Background $^{d}$ & Foreground & Background & Foreground & Background \\
\hline IA & $2.08(1)^{e}$ & $1.69(1)$ & & $3.26(0)$ & $1.57(0)$ & $1.21(2)$ & $2.04(1)$ \\
\hline IB & $3.54(0)$ & $1.36(0)$ & & $7.97(-1)$ & $1.03(-1)$ & $1.68(1)$ & $9.91(-1)$ \\
\hline IIA & $3.94(-2)$ & $9.15(-3)$ & & $2.60(-3)$ & $3.19(-4)$ & $1.07(-1)$ & $3.39(-3)$ \\
\hline IIB & $1.06(-3)$ & $1.11(-3)$ & $1.05(-3)$ & $5.70(-5)$ & $5.03(-5)$ & $1.20(-3)$ & $5.28(-4)$ \\
\hline IIC & $1.28(-3)$ & $1.15(-3)$ & $1.00(-3)$ & $8.02(-5)$ & $4.46(-5)$ & $9.15(-4)$ & $4.61(-4)$ \\
\hline IID & $1.10(-3)$ & $1.06(-3)$ & & $1.50(-4)$ & $7.29(-5)$ & $4.87(-3)$ & $8.71(-4)$ \\
\hline IIE & $7.37(-4)$ & $7.69(-4)$ & $7.43(-4)$ & $3.63(-5)$ & $3.68(-5)$ & $6.13(-4)$ & $3.51(-4)$ \\
\hline IIF & $7.78(-4)$ & $6.92(-4)$ & $6.70(-4)$ & $4.78(-5)$ & $3.31(-5)$ & $5.31(-4)$ & $3.06(-4)$ \\
\hline
\end{tabular}


Table 15. (continued)

\begin{tabular}{ccccccc}
\hline & \multicolumn{6}{c}{ Count rate $\left(\mathrm{s}^{-1} \mathrm{~W}^{-1}\right)$} \\
\cline { 2 - 7 } Configuration & \multicolumn{2}{c}{ 5-in-Diam Ball } & \multicolumn{2}{c}{ 8-in-Diam Ball } & \multicolumn{2}{c}{ 10-in-Diam Ball } \\
\cline { 2 - 7 } & Foreground & Background & Foreground & Background & Foreground & Background \\
IA & $5.49(2)$ & $4.83(1)$ & $3.86(2)$ & $2.36(1)$ & $1.94(2)$ & $1.13(1)$ \\
IIA & $5.87(1)$ & $1.91(0)$ & $3.77(1)$ & $8.56(-1)$ & $1.83(1)$ & $3.78(-1)$ \\
IIB & $4.02(-1)$ & $6.03(-3)$ & $2.22(-1)$ & $2.79(-3)$ & $9.24(-2)$ & $1.30(-3)$ \\
IIC & $5.10(-3)$ & $1.01(-3)$ & $3.95(-3)$ & $4.90(-4)$ & $2.23(-3)$ & $2.32(-4)$ \\
IID & $1.94(-3)$ & $8.06(-4)$ & $9.70(-4)$ & $3.98(-4)$ & $4.93(-4)$ & $1.77(-4)$ \\
IIE & $2.46(-2)$ & $1.97(-3)$ & $1.88(-2)$ & $9.97(-4)$ & $1.07(-2)$ & $4.91(-4)$ \\
IIF & $2.74(-3)$ & $6.72(-4)$ & $2.50(-3)$ & $3.42(-4)$ & $1.55(-3)$ & $1.56(-4)$ \\
\hline
\end{tabular}

${ }^{a}$ See experimental program plan in Appendix A for description of configurations.

${ }^{b}$ Count rates without shadow shield between detector and configuration.

${ }^{c}$ Count rates with shadow shield between detector and configuration.

${ }^{d}$ Count rates with cadmium over face of shadow shield.

${ }^{e}$ Read: $2.08 \times 10^{1}$. 
Table 16. Fast neutron fluxes ( $>0.8 \mathrm{MeV}$ ) on centerline at $40 \mathrm{~cm}$ behind the stainless steel (Item IB): Run 7927A

\begin{tabular}{|c|c|c|c|c|c|}
\hline \multirow[b]{2}{*}{$\begin{array}{l}\text { Neutron } \\
\text { Energy } \\
(\mathrm{MeV})\end{array}$} & \multicolumn{2}{|c|}{ Flux (neutrons $\mathrm{cm}^{-2} \mathrm{MeV}^{-1} \mathrm{~kW}^{-1} \mathrm{~s}^{-1}$ ) } & \multirow[b]{2}{*}{$\begin{array}{l}\text { Neutron } \\
\text { Energy } \\
(\mathrm{MeV})\end{array}$} & \multicolumn{2}{|c|}{ Flux (neutrons $\mathrm{cm}^{-2} \mathrm{MeV}^{-1} \mathrm{~kW}^{-1} \mathrm{~s}^{-1}$ ) } \\
\hline & $\begin{array}{l}\text { Lower } \\
\text { Limit }\end{array}$ & $\begin{array}{l}\text { Upper } \\
\text { Limit }\end{array}$ & & $\begin{array}{l}\text { Lower } \\
\text { Limit }\end{array}$ & $\begin{array}{l}\text { Upper } \\
\text { Limit }\end{array}$ \\
\hline 8.11E -01 & $3.04 E+04$ & $3.06 \mathrm{E}+04$ & $5.94 E+00$ & $1.76 \mathrm{E}+02$ & $1.90 \mathrm{E}+02$ \\
\hline $9.07 E-01$ & $2.89 E+04$ & $2.90 \mathrm{E}+04$ & $6.25 \mathrm{E}+00$ & $1.40 E+02$ & $1.54 \mathrm{E}+02$ \\
\hline $1.01 E+00$ & $2.39 E+04$ & $2.40 \mathrm{E}+04$ & $6.55 \mathrm{E}+00$ & $1.18 \mathrm{E}+02$ & $1.30 \mathrm{E}+02$ \\
\hline $1.11 E+00$ & $1.94 E+04$ & $1.95 \mathrm{E}+04$ & $6.84 \mathrm{E}+00$ & $1.07 \mathrm{E}+02$ & $1.17 \mathrm{E}+02$ \\
\hline $1.20 \mathrm{E}+00$ & $1.59 \mathrm{E}+04$ & $1.59 \mathrm{E}+04$ & $7.24 \mathrm{E}+00$ & $9.76 \mathrm{E}+01$ & $1.05 E+02$ \\
\hline $1.31 E+00$ & $1.28 \mathrm{E}+04$ & $1.29 E+04$ & $7.74 \mathrm{E}+00$ & $7.86 \mathrm{E}+01$ & $8.95 E+01$ \\
\hline $1.41 E+00$ & $1.05 E+04$ & $1.06 \mathrm{E}+04$ & $8.24 \mathrm{E}+00$ & $6.33 E+01$ & $7.55 \mathrm{E}+01$ \\
\hline $1.51 E+00$ & $8.79 E+03$ & $8.85 E+03$ & $8.76 \mathrm{E}+00$ & $5.54 E+01$ & $6.11 E+01$ \\
\hline $1.61 E+00$ & $7.40 E+03$ & $7.45 E+03$ & $9.26 \mathrm{E}+00$ & $4.60 E+01$ & $5.13 E+01$ \\
\hline $1.71 E+00$ & $6.26 \mathrm{E}+03$ & $6.31 E+03$ & $9.74 E+00$ & $4.20 \mathrm{E}+01$ & $4.63 \mathrm{E}+01$ \\
\hline $1.81 E+00$ & $5.34 E+03$ & $5.39 E+03$ & $1.03 E+01$ & $4.11 E+01$ & $4.52 E+01$ \\
\hline $1.93 E+00$ & $4.50 E+03$ & $4.54 E+03$ & $1.08 \mathrm{E}+01$ & $3.75 \mathrm{E}+01$ & $4.12 \mathrm{E}+01$ \\
\hline $2.10 \mathrm{E}+00$ & $3.57 E+03$ & $3.61 E+03$ & $1.12 \mathrm{E}+01$ & $3.04 E+01$ & $3.34 \mathrm{E}+01$ \\
\hline $2.30 \mathrm{E}+00$ & $2.76 E+03$ & $2.80 \mathrm{E}+03$ & $1.18 \mathrm{E}+01$ & $2.27 \mathrm{E}+01$ & $2.51 E+01$ \\
\hline $2.50 \mathrm{E}+00$ & $2.15 E+03$ & $2.18 \mathrm{E}+03$ & $1.24 \mathrm{E}+01$ & $1.59 E+01$ & $1.81 E+01$ \\
\hline $2.70 \mathrm{E}+00$ & $1.73 E+03$ & $1.76 E+03$ & $1.32 \mathrm{E}+01$ & $8.63 E+00$ & $1.01 E+01$ \\
\hline $2.90 \mathrm{E}+00$ & $1.47 E+03$ & $1.50 \mathrm{E}+03$ & $1.40 \mathrm{E}+01$ & $1.53 E+00$ & $2.80 \mathrm{E}+00$ \\
\hline $3.10 \mathrm{E}+00$ & $1.25 \mathrm{E}+03$ & $1.28 \mathrm{E}+03$ & $1.48 \mathrm{E}+01$ & $-3.88 \mathrm{E}-01$ & $6.90 \mathrm{E}-01$ \\
\hline $3.30 \mathrm{E}+00$ & $9.97 \mathrm{E}+02$ & $1.02 \mathrm{E}+03$ & $1.56 \mathrm{E}+01$ & $1.94 E+00$ & $2.88 \mathrm{E}+00$ \\
\hline $3.50 \mathrm{E}+00$ & $7.83 E+02$ & $8.10 \mathrm{E}+02$ & $1.65 E+01$ & $2.50 \mathrm{E}+00$ & $3.38 E+00$ \\
\hline $3.71 \mathrm{E}+00$ & $6.32 E+02$ & $6.52 E+02$ & $1.75 E+01$ & $2.44 \mathrm{E}-01$ & $8.48 \mathrm{E}-01$ \\
\hline $3.91 E+00$ & $5.20 \mathrm{E}+02$ & $5.38 \mathrm{E}+02$ & $1.85 \mathrm{E}+01$ & $-3.02 E-01$ & $1.86 \mathrm{E}-01$ \\
\hline $4.15 \mathrm{E}+00$ & $4.34 \mathrm{E}+02$ & $4.51 \mathrm{E}+02$ & $1.95 \mathrm{E}+01$ & $-7.16 \mathrm{E}-02$ & $3.87 \mathrm{E}-01$ \\
\hline $4.45 \mathrm{E}+00$ & $3.81 E+02$ & $3.95 \mathrm{E}+02$ & $2.05 E+01$ & $-5.22 \mathrm{E}-01$ & $1.67 \mathrm{E}-01$ \\
\hline $4.75 E+\infty 0$ & $3.32 E+02$ & $3.45 \mathrm{E}+02$ & $2.16 \mathrm{E}+01$ & $-6.63 E-01$ & $6.13 E-02$ \\
\hline $5.04 \mathrm{E}+00$ & $2.86 \mathrm{E}+02$ & $2.98 \mathrm{E}+02$ & $2.26 \mathrm{E}+01$ & $-3.11 E-01$ & $1.85 \mathrm{E}-01$ \\
\hline $5.34 \mathrm{E}+00$ & $2.47 \mathrm{E}+02$ & $2.59 \mathrm{E}+02$ & $2.35 \mathrm{E}+01$ & $-1.30 \mathrm{E}-01$ & $2.93 \mathrm{E}-01$ \\
\hline $5.64 \mathrm{E}+00$ & $2.12 \mathrm{E}+02$ & $2.26 \mathrm{E}+02$ & & & \\
\hline
\end{tabular}

\begin{tabular}{cccc}
$\begin{array}{c}\mathrm{E} 1 \\
(\mathrm{MeV})\end{array}$ & $\begin{array}{c}\mathrm{E} 2 \\
(\mathrm{MeV})\end{array}$ & $\begin{array}{c}\text { Integral } \\
\text { neutrons cm } \mathrm{kW}^{-1} \mathrm{~s}^{-1}\end{array}$ & $\begin{array}{c}\text { Error } \\
\text { neutrons } \mathrm{cm}^{-2} \mathrm{~kW}^{-1} \mathrm{~s}^{-1}\end{array}$ \\
\hline 0.811 & 1.000 & $5.37 \mathrm{E}+03$ & $1.40 \mathrm{E}+01$ \\
1.000 & 1.200 & $3.97 \mathrm{E}+03$ & $9.69 \mathrm{E}+00$ \\
1.200 & 1.600 & $4.44 \mathrm{E}+03$ & $1.42 \mathrm{E}+01$ \\
1.600 & 2.000 & $2.23 \mathrm{E}+03$ & $9.85 \mathrm{E}+00$ \\
2.000 & 3.000 & $2.36 \mathrm{E}+03$ & $1.71 \mathrm{E}+01$ \\
3.000 & 4.000 & $8.48 \mathrm{E}+02$ & $1.20 \mathrm{E}+01$ \\
4.000 & 6.000 & $6.19 \mathrm{E}+02$ & $1.37 \mathrm{E}+01$ \\
6.000 & 8.000 & $2.25 \mathrm{E}+02$ & $1.08 \mathrm{E}+01$ \\
8.000 & 10.000 & $1.10 \mathrm{E}+02$ & $6.71 \mathrm{E}+00$ \\
10.000 & 12.000 & $6.92 \mathrm{E}+01$ & $3.31 \mathrm{E}+00$ \\
12.000 & 16.000 & $2.50 \mathrm{E}+01$ & $2.75 \mathrm{E}+00$ \\
16.000 & 20.000 & $3.37 \mathrm{E}+00$ & $1.22 \mathrm{E}+00$ \\
3.000 & 10.000 & $1.80 \mathrm{E}+03$ & $4.35 \mathrm{E}+01$ \\
1.500 & 15.000 & $7.31 \mathrm{E}+03$ & $7.91 \mathrm{E}+01$ \\
3.000 & 12.000 & $1.87 \mathrm{E}+03$ & $4.68 \mathrm{E}+01$ \\
\hline
\end{tabular}


Table 17. Neutron fluxes ( $50 \mathrm{keV}$ to $1.4 \mathrm{MeV}$ ) on centerline at $40 \mathrm{~cm}$ behind the stainless steel (Item IB) Runs 1598.C, 1598.B, 1598.A

\begin{tabular}{|c|c|c|c|c|}
\hline $\mathbf{N}$ & \multicolumn{2}{|c|}{$\begin{array}{l}\text { Energy Boundary } \\
(\mathrm{MeV})\end{array}$} & $\begin{array}{c}\text { Flux } \\
\text { (neutrons } \mathrm{cm}^{-2} \mathrm{MeV}^{-1} \mathrm{~kW}^{-1} \mathrm{~s}^{-1} \text { ) }\end{array}$ & $\begin{array}{l}\text { Error } \\
(\%)\end{array}$ \\
\hline \multicolumn{5}{|c|}{ RUN 1598.C } \\
\hline 1 & 0.0387 & 0.0456 & $9.90 \mathrm{E}+05$ & 2.64 \\
\hline 2 & 0.0456 & 0.0542 & $9.67 E+05$ & 2.42 \\
\hline 3 & 0.0542 & 0.0645 & $8.24 E+05$ & 2.64 \\
\hline 4 & 0.0645 & 0.0748 & $9.13 E+05$ & 2.67 \\
\hline 5 & 0.0748 & 0.0886 & $9.24 \mathrm{E}+05$ & 2.09 \\
\hline 6 & 0.0886 & 0.1040 & $5.88 \mathrm{E}+05$ & 3.17 \\
\hline 7 & 0.1040 & 0.1212 & $5.79 E+05$ & 3.20 \\
\hline 8 & 0.1212 & 0.1436 & $7.94 E+05$ & 1.84 \\
\hline 9 & 0.1436 & 0.1694 & $4.96 E+05$ & 2.67 \\
\hline 10 & 0.1694 & 0.1986 & $3.61 E+05$ & 3.47 \\
\hline 11 & 0.1986 & 0.2347 & $2.78 \mathrm{E}+05$ & 3.82 \\
\hline 12 & 0.2347 & 0.2760 & $3.04 E+05$ & 3.24 \\
\hline \multicolumn{5}{|c|}{$\underline{\text { RUN 1598.B }}$} \\
\hline 1 & 0.1988 & 0.2344 & $2.70 \mathrm{E}+05$ & 1.56 \\
\hline 2 & 0.2344 & 0.2760 & $3.04 E+05$ & 1.29 \\
\hline 3 & 0.2760 & 0.3235 & $3.01 E+05$ & 1.20 \\
\hline 4 & 0.3235 & 0.3769 & $2.04 E+05$ & 1.63 \\
\hline 5 & 0.3769 & 0.4481 & $1.36 \mathrm{E}+05$ & 1.86 \\
\hline 6 & 0.4481 & 0.5253 & $1.14 E+05$ & 2.19 \\
\hline 7 & 0.5253 & 0.6203 & $1.14 E+05$ & 1.73 \\
\hline \multicolumn{5}{|c|}{ RUN 1598.A } \\
\hline 1 & 0.4430 & 0.5257 & $1.07 E+05$ & 1.36 \\
\hline 2 & 0.5257 & 0.6203 & $1.07 E+05$ & 1.25 \\
\hline 3 & 0.6203 & 0.7266 & $9.79 E+04$ & 1.21 \\
\hline 4 & 0.7266 & 0.8565 & $6.04 E+04$ & 1.53 \\
\hline 5 & 0.8565 & 1.0101 & $3.06 \mathrm{E}+04$ & 2.49 \\
\hline 6 & 1.0101 & 1.1873 & $2.09 E+04$ & 3.18 \\
\hline 7 & 1.1873 & 1.4000 & $1.43 E+04$ & 3.79 \\
\hline
\end{tabular}


Table 18. Bonner ball measurements on centerline at NE 213 location behind a series of configurations

\begin{tabular}{|c|c|c|c|c|}
\hline \multirow[b]{2}{*}{ Configuration $^{a}$} & \multirow[b]{2}{*}{$\begin{array}{l}\text { Detector } \\
\text { Location }\end{array}$} & \multicolumn{3}{|c|}{ Count rates $\left(s^{-1} W^{-1}\right)$} \\
\hline & & $\begin{array}{c}\text { 3-in-Diam } \\
\text { Ball } \\
\end{array}$ & $\begin{array}{c}\begin{array}{c}5 \text {-in-Diam } \\
\text { Ball }\end{array} \\
\end{array}$ & $\begin{array}{c}\text { 10-in-Diam } \\
\text { Ball } \\
\end{array}$ \\
\hline IB & $\begin{array}{c}40 \mathrm{~cm} \\
\text { behind SS }\end{array}$ & $1.48(2)^{b}$ & $5.59(2)$ & $1.68(2)$ \\
\hline IIA & $\begin{array}{c}25 \mathrm{~cm} \\
\text { behind lead }^{c}\end{array}$ & $5.83(-1)$ & $2.36(0)$ & $5.85(-1)$ \\
\hline
\end{tabular}

${ }^{a}$ See experimental program plan in Appendix A for description of configurations.

${ }^{b}$ Read: $1.48 \times 10^{2}$.

${ }^{c}$ Lead slab between configuration and detector (see schematics). 
Table 19. 5-inch Bonner ball horizontal traverses through midplane at $30 \mathrm{~cm}$ behind mockup

\begin{tabular}{|c|c|c|c|c|c|}
\hline \multirow{2}{*}{$\begin{array}{c}\text { Distance } \\
\text { from } \\
\text { Centerline } \\
(\mathrm{cm}) \\
\end{array}$} & \multicolumn{5}{|c|}{ Count rates $\left(\mathrm{s}^{-1} \mathrm{~W}^{-1}\right)$} \\
\hline & ${\underline{\text { Item } \mathrm{IB}^{a}}}$ & Item IIA & Item IIB & Item IID & Item IIE \\
\hline $96 \mathrm{~S}$ & $1.75(1)^{b}$ & & & & \\
\hline 95 & & & $3.66(-3)$ & & $1.94(-3)$ \\
\hline 90 & $2.27(1)$ & & & & $2.26(-3)$ \\
\hline 85 & & & $5.07(-3)$ & & \\
\hline 80 & $3.26(1)$ & $1.18(-1)$ & & $2.65(-2)$ & $3.01(-3)$ \\
\hline 75 & & & $7.15(-3)$ & & \\
\hline 70 & $4.47(1)$ & $1.72(-1)$ & & $3.75(-2)$ & $4.15(-3)$ \\
\hline 60 & $6.98(1)$ & $2.44(-1)$ & $1.10(-2)$ & $5.56(-2)$ & $5.67(-3)$ \\
\hline 55 & & & $1.28(-2)$ & & \\
\hline 50 & $1.23(2)$ & $3.76(-1)$ & & $8.13(-2)$ & $7.62(-3)$ \\
\hline 45 & & & $1.64(-2)$ & $9.63(-2)$ & \\
\hline 40 & $2.36(2)$ & $6.17(-1)$ & & $1.12(-1)$ & $9.73(-3)$ \\
\hline 35 & & $7.66(-1)$ & $2.05(-2)$ & $1.29(-1)$ & \\
\hline 30 & $4.29(2)$ & $1.08(0)$ & & $1.44(-1)$ & $1.21(-2)$ \\
\hline 27.5 & & $1.24(0)$ & & & \\
\hline 25 & & $1.48(0)$ & $2.50(-2)$ & $1.59(-1)$ & \\
\hline 20 & $6.07(2)$ & $2.06(0)$ & $2.68(-2)$ & $1.75(-1)$ & $1.38(-2)$ \\
\hline 15 & & $2.73(0)$ & $2.88(-2)$ & $1.86(-1)$ & \\
\hline 10 & $7.30(2)$ & $3.48(0)$ & $3.00(-2)$ & $1.93(-1)$ & $1.51(-2)$ \\
\hline 5 & & & $3.07(-2)$ & $2.00(-1)$ & \\
\hline $\mathbf{0}$ & $7.54(2)$ & $4.13(0)$ & $3.14(-2)$ & $2.02(-1)$ & $1.54(-2)$ \\
\hline 5 & & & & $2.04(-1)$ & \\
\hline 10 & $7.19(2)$ & $3.65(0)$ & $3.02(-2)$ & $1.94(-1)$ & $1.50(-2)$ \\
\hline 15 & & $2.95(0)$ & & $1.86(-1)$ & \\
\hline 20 & $5.96(2)$ & $2.17(0)$ & $2.73(-2)$ & $1.74(-1)$ & $1.38(-2)$ \\
\hline 25 & & $1.56(0)$ & & $1.60(-1)$ & \\
\hline 30 & $4.19(2)$ & $1.13(0)$ & $2.32(-2)$ & $1.42(-1)$ & $1.19(-2)$ \\
\hline 35 & & $8.60(-1)$ & & $1.26(-1)$ & \\
\hline 40 & $2.43(2)$ & $6.40(-1)$ & $1.88(-2)$ & $1.10(-1)$ & $9.73(-3)$ \\
\hline 45 & & & & $9.47(-2)$ & \\
\hline 50 & $1.31(2)$ & $4.00(-1)$ & $1.47(-2)$ & $7.97(-2)$ & $7.58(-3)$ \\
\hline 55 & & & & $6.51(-2)$ & \\
\hline 60 & $7.68(1)$ & $2.51(-1)$ & $1.13(-2)$ & & $5.64(-3)$ \\
\hline 69 & & & $8.88(-3)$ & & \\
\hline 70 & $4.76(1)$ & $1.70(-1)$ & & & $4.15(-3)$ \\
\hline 80 & $3.37(1)$ & $1.20(-1)$ & & & $3.04(-3)$ \\
\hline 85 & & & & & $2.66(-3)$ \\
\hline $90 \mathrm{~N}$ & $2.42(1)$ & & & & \\
\hline
\end{tabular}

${ }^{a}$ See experimental program plan in Appendix A for description of configurations.

${ }^{b}$ Read: $1.75 \times 10^{1}$. 
Table 20. Bare and Cd-covered fission chamber horizontal traverses through midplane at $30 \mathrm{~cm}$ behind mockup

\begin{tabular}{|c|c|c|c|c|}
\hline \multirow{3}{*}{$\begin{array}{l}\text { Distance from } \\
\text { Centerline } \\
\text { (cm) }\end{array}$} & \multicolumn{4}{|c|}{ Count rates $\left(\mathrm{s}^{-1} \mathrm{~W}^{-1}\right)$} \\
\hline & \multicolumn{2}{|c|}{ Item IB $^{a}$} & \multicolumn{2}{|c|}{ Item IIA } \\
\hline & $\underline{\text { Bare Detector }}$ & $\begin{array}{c}\text { Cd-covered } \\
\text { Detector } \\
\end{array}$ & Bare Detector & $\begin{array}{l}\text { Cd-covered } \\
\text { Detector } \\
\end{array}$ \\
\hline $100 \mathrm{~S}$ & $6.03(-2)^{b}$ & $1.07(-2)$ & & \\
\hline 90 & $7.27(-2)$ & $1.51(-2)$ & & \\
\hline 80 & $9.16(-2)$ & $2.13(-2)$ & $1.38(-3)$ & $3.82(-5)$ \\
\hline 70 & $1.10(-1)$ & $2.71(-2)$ & $1.82(-3)$ & $5.23(-5)$ \\
\hline 60 & $1.41(-1)$ & $3.74(-2)$ & $2.22(-3)$ & $7.17(-5)$ \\
\hline 50 & $1.92(-1)$ & $5.90(-2)$ & $2.63(-3)$ & $1.05(-4)$ \\
\hline 40 & $2.76(-1)$ & $1.01(-1)$ & $2.83(-3)$ & $1.53(-4)$ \\
\hline 30 & $3.80(-1)$ & $1.67(-1)$ & $2.78(-3)$ & $2.37(-4)$ \\
\hline 27.5 & & & $2.74(-3)$ & \\
\hline 25 & & & $2.69(-3)$ & $3.06(-4)$ \\
\hline 20 & $4.93(-1)$ & $2.33(-1)$ & $2.70(-3)$ & $4.18(-4)$ \\
\hline 15 & & & $2.79(-3)$ & $5.92(-4)$ \\
\hline 10 & $5.56(-1)$ & $2.69(-1)$ & $2.86(-3)$ & $7.76(-4)$ \\
\hline 5 & & & $2.93(-3)$ & $8.86(-4)$ \\
\hline 0 & $5.71(-1)$ & $2.81(-1)$ & $2.98(-3)$ & $9.20(-4)$ \\
\hline 5 & & & $2.94(-3)$ & $8.97(-4)$ \\
\hline 10 & $5.50(-1)$ & $2.71(-1)$ & $2.91(-3)$ & $8.01(-4)$ \\
\hline 15 & & & $2.85(-3)$ & $6.35(-4)$ \\
\hline 20 & $4.88(-1)$ & $2.28(-1)$ & $2.80(-3)$ & $4.47(-4)$ \\
\hline 25 & & & $2.84(-3)$ & $3.23(-4)$ \\
\hline 27.5 & & & $2.93(-3)$ & \\
\hline 30 & $3.72(-1)$ & $1.66(-1)$ & $2.96(-3)$ & $2.46(-4)$ \\
\hline 40 & $2.59(-1)$ & $1.03(-1)$ & $2.98(-3)$ & $1.59(-4)$ \\
\hline 50 & $1.84(-1)$ & $6.25(-2)$ & $2.80(-3)$ & $1.11(-4)$ \\
\hline 60 & $1.39(-1)$ & $4.01(-2)$ & $2.38(-3)$ & $7.70(-5)$ \\
\hline 70 & $1.06(-1)$ & $2.78(-2)$ & $1.89(-3)$ & $5.36(-5)$ \\
\hline $80 \mathrm{~N}$ & $8.68(-2)$ & $2.07(-2)$ & $1.48(-3)$ & $3.86(-5)$ \\
\hline
\end{tabular}

${ }^{a}$ See experimental program plan in Appendix A for description of configurations.

${ }^{b}$ Read: $6.03 \times 10^{-2}$. 
Table 21. Fast neutron fluxes ( $>0.8 \mathrm{MeV}$ ) on centerline at $25 \mathrm{~cm}$ behind the lead slab (Item IIA) Run 7930A

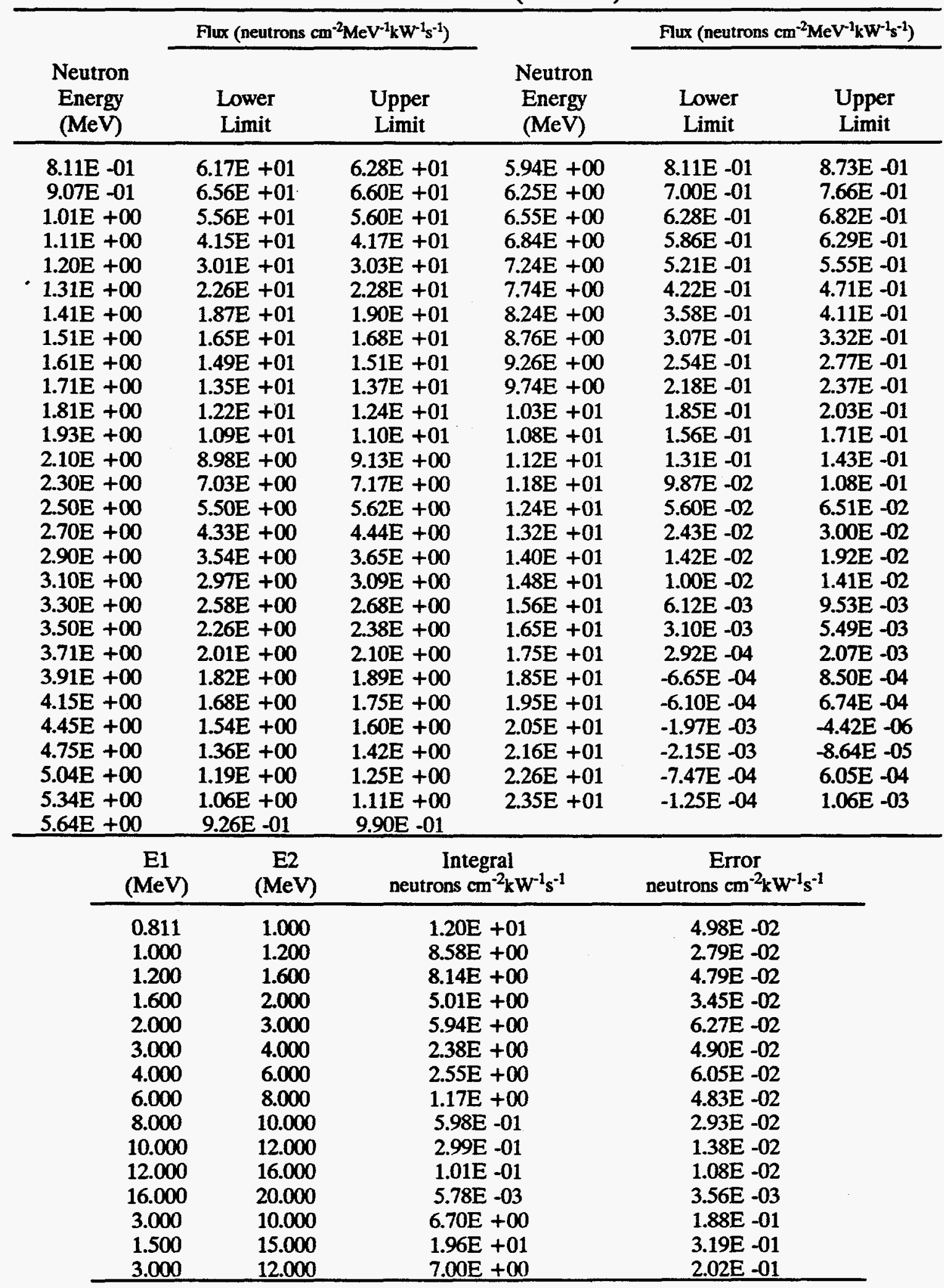


Table 22 Neutron spectrum ( $50 \mathrm{keV}$ to $1.4 \mathrm{MeV}$ ) on centerline at $25 \mathrm{~cm}$ behind the lead (Item IIA) Runs 1601.A, 1600.B, 1601.B

\begin{tabular}{|c|c|c|c|c|}
\hline $\mathbf{N}$ & Ener & ndary & $\underset{\text { (neutrons } \mathrm{cm}^{-2} \mathrm{MeV}^{-1} \mathrm{~kW}^{-1} \mathrm{~s}^{-1} \text { ) }}{\text { Flux }}$ & $\begin{array}{c}\text { Error } \\
(\%)\end{array}$ \\
\hline \multicolumn{5}{|c|}{ RUN 1601.A } \\
\hline 1 & 0.0394 & 0.0464 & $4.27 E+03$ & 1.92 \\
\hline 2 & 0.0464 & 0.0551 & $4.09 E+03$ & 1.75 \\
\hline 3 & 0.0551 & 0.0639 & $4.85 E+03$ & 1.58 \\
\hline 4 & 0.0639 & 0.0744 & $4.75 E+03$ & 1.35 \\
\hline 5 & 0.0744 & 0.0884 & $2.73 E+03$ & 1.71 \\
\hline 6 & 0.0884 & 0.1041 & $1.03 E+03$ & 4.27 \\
\hline 7 & 0.1041 & 0.1216 & $1.35 \mathrm{E}+03$ & 3.21 \\
\hline 8 & 0.1216 & 0.1443 & $1.72 E+03$ & 1.93 \\
\hline 9 & 0.1443 & 0.1688 & $7.22 \mathrm{E}+02$ & 4.47 \\
\hline 10 & 0.1688 & 0.1986 & $5.23 E+02$ & 5.38 \\
\hline 11 & 0.1986 & 0.2353 & $4.99 E+02$ & 4.77 \\
\hline \multicolumn{5}{|c|}{ RUN 1600.B } \\
\hline 1 & 0.1681 & 0.1986 & $5.23 \mathrm{E}+02$ & 2.22 \\
\hline 2 & 0.1986 & 0.2353 & $4.86 \mathrm{E}+02$ & 2.20 \\
\hline 3 & 0.2353 & 0.2720 & $6.19 E+02$ & 1.88 \\
\hline 4 & 0.2720 & 0.3209 & $4.89 E+02$ & 1.80 \\
\hline 5 & 0.3209 & 0.3820 & $3.00 \mathrm{E}+02$ & 2.41 \\
\hline 6 & 0.3820 & 0.4431 & $2.17 E+02$ & 3.64 \\
\hline 7 & 0.4431 & 0.5226 & $1.61 \mathrm{E}+02$ & 3.83 \\
\hline 8 & 0.5226 & 0.6204 & $1.46 \mathrm{E}+02$ & 3.48 \\
\hline \multicolumn{5}{|c|}{ RUN 1601.B } \\
\hline 1 & 0.4447 & 0.5216 & $1.59 \mathrm{E}+02$ & 2.62 \\
\hline 2 & 0.5216 & 0.6204 & $1.42 \mathrm{E}+02$ & 2.36 \\
\hline 3 & 0.6204 & 0.7302 & $1.11 E+02$ & 2.82 \\
\hline 4 & 0.7302 & 0.8510 & $8.26 E+01$ & 3.53 \\
\hline 5 & 0.8510 & 1.0047 & $6.36 \mathrm{E}+01$ & 3.51 \\
\hline 6 & 1.0047 & 1.1804 & $3.99 \mathrm{E}+01$ & 4.79 \\
\hline 7 & 1.1804 & 1.4000 & $2.14 E+01$ & 6.88 \\
\hline
\end{tabular}


Table 23. Bare and Cd-covered fission chamber horizontal traverses through midplane at $5 \mathrm{~cm}$ behind axial shield in the void

\begin{tabular}{|c|c|c|c|c|}
\hline \multirow[b]{3}{*}{$\begin{array}{l}\text { Distance from } \\
\text { Centerline } \\
(\mathrm{cm}) \\
\end{array}$} & \multicolumn{4}{|c|}{ Count rates $\left(\mathrm{s}^{-1} \mathrm{~W}^{-1}\right)$} \\
\hline & \multicolumn{2}{|c|}{ Item IIB ${ }^{a}$} & \multicolumn{2}{|c|}{ Item IIE } \\
\hline & Bare Detector & $\begin{array}{c}\text { Cd-covered } \\
\text { Detector } \\
\end{array}$ & Bare Detector & $\begin{array}{c}\text { Cd-covered } \\
\text { Detector }\end{array}$ \\
\hline $65 \mathrm{~S}$ & $4.51(-3)^{b}$ & $2.23(-4)$ & $6.70(-3)$ & $3.89(-4)$ \\
\hline 60 & $5.15(-3)$ & $2.40(-4)$ & $7.39(-3)$ & $4.15(-4)$ \\
\hline 55 & & & $8.19(-3)$ & $4.53(-4)$ \\
\hline 50 & $6.42(-3)$ & $2.82(-4)$ & $8.88(-3)$ & $5.01(-4)$ \\
\hline 45 & & & $9.47(-3)$ & $5.53(-4)$ \\
\hline 40 & $6.98(-3)$ & $3.52(-4)$ & $9.46(-3)$ & $6.00(-4)$ \\
\hline 35 & $6.03(-3)$ & $3.84(-4)$ & $8.25(-3)$ & $6.36(-4)$ \\
\hline 30 & $4.42(-3)$ & $3.87(-4)$ & $5.98(-3)$ & $6.22(-4)$ \\
\hline 27.5 & $3.56(-3)$ & $3.92(-4)$ & $4.96(-3)$ & \\
\hline 25 & $3.07(-3)$ & $4.20(-4)$ & $4.38(-3)$ & $6.60(-4)$ \\
\hline 22.5 & $2.79(-3)$ & $4.72(-4)$ & $4.12(-3)$ & \\
\hline 20 & $2.66(-3)$ & $5.50(-4)$ & $4.02(-3)$ & $8.22(-4)$ \\
\hline 17.5 & $2.55(-3)$ & $6.91(-4)$ & $4.06(-3)$ & \\
\hline 15 & $2.75(-3)$ & $9.41(-4)$ & $4.30(-3)$ & $1.26(-3)$ \\
\hline 12.5 & $3.22(-3)$ & $1.38(-3)$ & $4.80(-3)$ & \\
\hline 10 & $4.02(-3)$ & $2.18(-3)$ & $5.80(-3)$ & $2.55(-3)$ \\
\hline 7.5 & $4.78(-3)$ & $2.92(-3)$ & $6.55(-3)$ & \\
\hline 5 & $5.09(-3)$ & $3.33(-3)$ & $6.81(-3)$ & $3.52(-3)$ \\
\hline 2.5 & $5.31(-3)$ & $3.55(-3)$ & $6.96(-3)$ & \\
\hline 0 & $5.36(-3)$ & $3.66(-3)$ & $7.15(-3)$ & $3.68(-3)$ \\
\hline 2.5 & $5.41(-3)$ & $3.57(-3)$ & $6.89(-3)$ & \\
\hline 5 & $5.11(-3)$ & $3.41(-3)$ & $6.60(-3)$ & $3.39(-3)$ \\
\hline 7.5 & $4.83(-3)$ & $3.12(-3)$ & $6.04(-3)$ & \\
\hline 10 & $4.14(-3)$ & $2.46(-3)$ & $5.19(-3)$ & $2.22(-3)$ \\
\hline 12.5 & $3.32(-3)$ & $1.66(-3)$ & $4.42(-3)$ & \\
\hline 15 & $2.78(-3)$ & $1.08(-3)$ & $4.14(-3)$ & $1.14(-3)$ \\
\hline 17.5 & $2.60(-3)$ & $7.86(-4)$ & $4.07(-3)$ & \\
\hline 20 & $2.61(-3)$ & $6.15(-4)$ & $4.12(-3)$ & $7.77(-4)$ \\
\hline 22.5 & $2.72(-3)$ & $4.98(-4)$ & $4.27(-3)$ & \\
\hline 25 & $3.05(-3)$ & $4.49(-4)$ & $4.73(-3)$ & $6.58(-4)$ \\
\hline 27.5 & $3.59(-3)$ & $4.02(-4)$ & $5.61(-3)$ & \\
\hline 30 & $4.43(-3)$ & $3.90(-4)$ & $6.82(-3)$ & $6.44(-4)$ \\
\hline 32.5 & & $3.92(-4)$ & $8.19(-3)$ & \\
\hline 35 & $6.39(-3)$ & $3.96(-4)$ & $9.13(-3)$ & $6.33(-4)$ \\
\hline 40 & $7.53(-3)$ & $3.80(-4)$ & $1.01(-2)$ & $6.06(-4)$ \\
\hline 45 & $7.63(-3)$ & $3.39(-4)$ & $9.88(-3)$ & $5.58(-4)$ \\
\hline $50 \mathrm{~N}$ & $7.05(-3)$ & $3.05(-4)$ & $9.16(-3)$ & $5.01(-4)$ \\
\hline
\end{tabular}

${ }^{a}$ See experimental program plan in Appendix A for description of configurations.

${ }^{b}$ Read: $4.51 \times 10^{-3}$. 
Table 24. 5-inch Bonner ball horizontal traverse through midplane behind axial shield in the void

\begin{tabular}{|c|c|c|}
\hline \multirow{2}{*}{$\begin{array}{l}\text { Distance from } \\
\text { Centerline } \\
\text { (cm) }\end{array}$} & \multicolumn{2}{|c|}{ Count rates $\left(s^{-1} W^{-1}\right)$} \\
\hline & $\underline{\text { Item IIB }}^{a b}$ & $\underline{\text { Item IIE }}^{c}$ \\
\hline $65 \mathrm{~S}$ & $4.65(-1)^{d}$ & $6.91(-1)$ \\
\hline 60 & $5.39(-1)$ & $8.04(-1)$ \\
\hline 50 & $7.45(-1)$ & $1.14(0)$ \\
\hline 40 & $1.07(0)$ & $1.62(0)$ \\
\hline 35 & $1.37(0)$ & \\
\hline 30 & $1.78(0)$ & $2.54(0)$ \\
\hline 25 & $2.36(0)$ & $3.21(0)$ \\
\hline 20 & $3.32(0)$ & $4.24(0)$ \\
\hline 15 & $4.89(0)$ & $5.96(0)$ \\
\hline 10 & $6.87(0)$ & $7.84(0)$ \\
\hline 5 & $8.06(0)$ & $9.31(0)$ \\
\hline 0 & $8.43(0)$ & $9.55(0)$ \\
\hline 5 & $7.95(0)$ & $9.01(0)$ \\
\hline 10 & $6.68(0)$ & $7.49(0)$ \\
\hline 15 & $4.85(0)$ & $5.48(0)$ \\
\hline 20 & $3.36(0)$ & $4.00(0)$ \\
\hline 25 & $2.44(0)$ & $3.05(0)$ \\
\hline 30 & $1.80(0)$ & $2.40(0)$ \\
\hline 35 & $1.40(0)$ & \\
\hline 40 & $1.12(0)$ & $1.58(0)$ \\
\hline $50 \mathrm{~N}$ & $7.49(-1)$ & $1.09(0)$ \\
\hline
\end{tabular}

${ }^{a}$ See experimental program plan in Appendix A for description of configurations.

${ }^{b}$ Detector located at $17 \mathrm{~cm}$ behind axial shield concrete piece.

${ }^{c}$ Detector located at $16 \mathrm{~cm}$ behind axial shield concrete piece.

${ }^{d}$ Read: $4.65 \times 10^{-1}$. 

APPENDIX C

FIGURES 

Top View

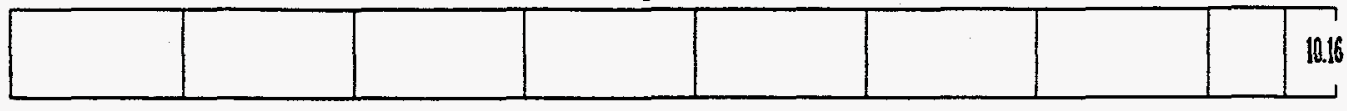

Front View
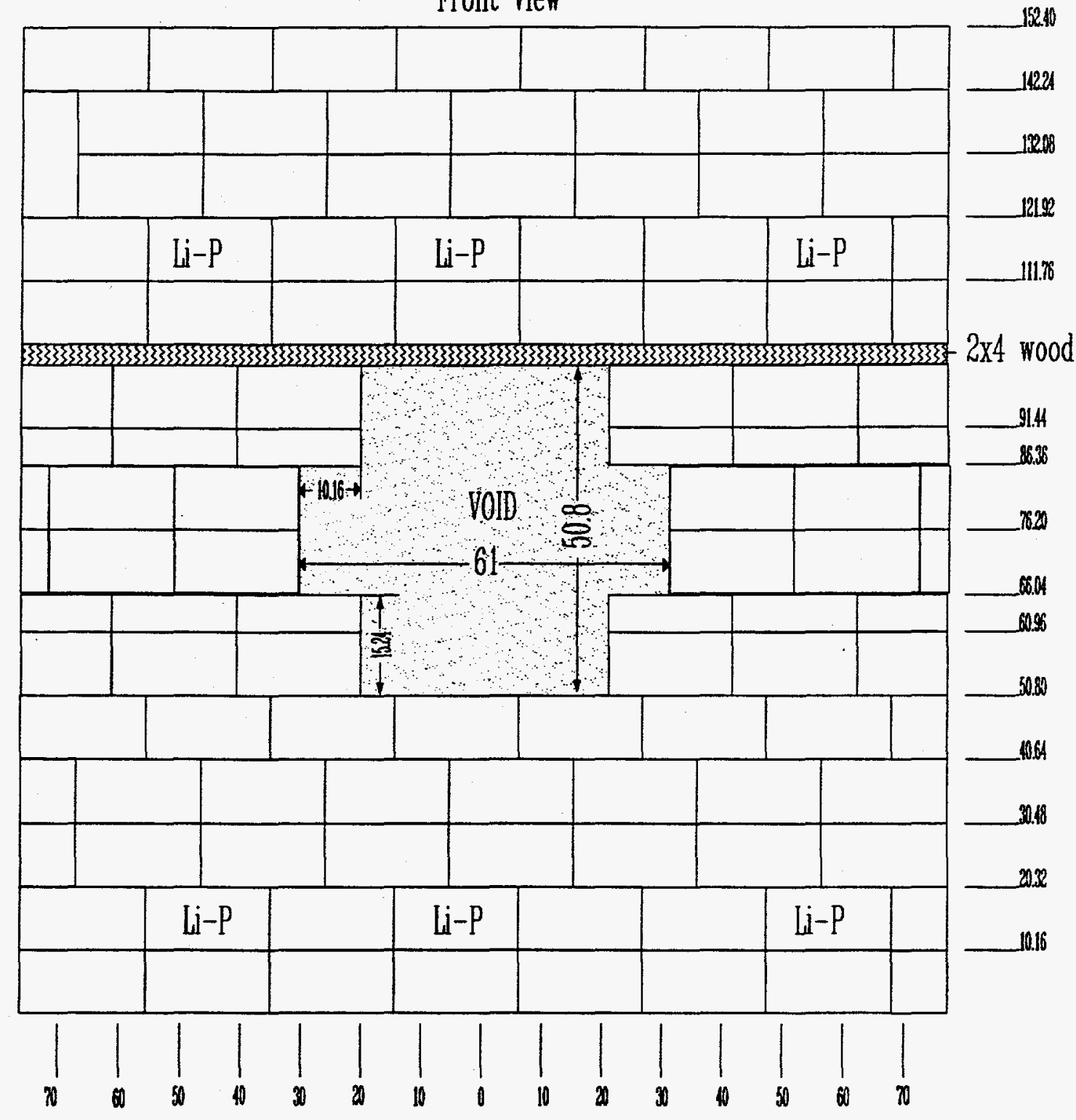

Figure 1. Schematic of the lithiated paraffin slabs with iris. 


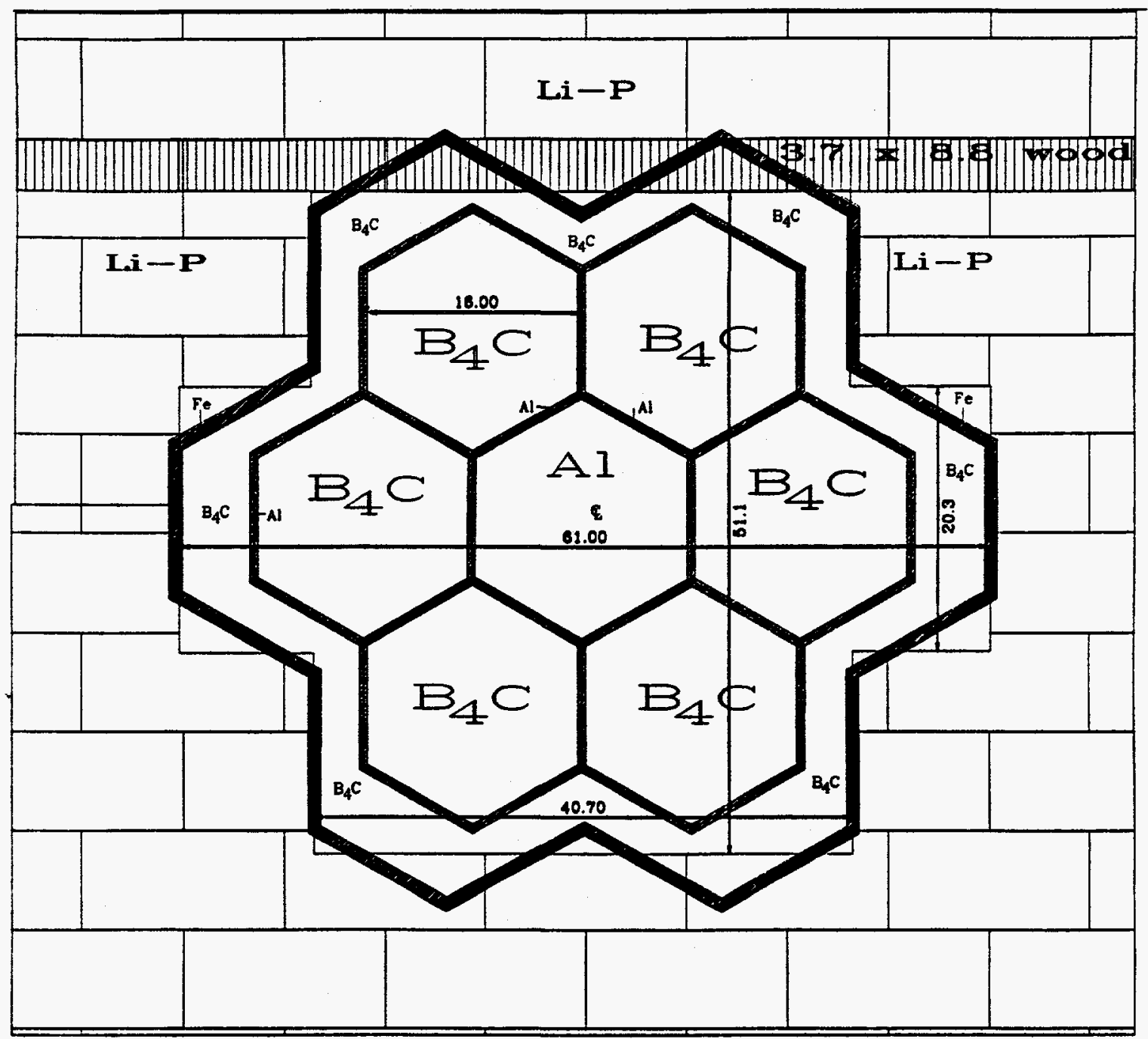

Figure 2. Schematic of the superimposed lithiated paraffin slab iris upon the seven-hexagon arrangement in the axial shield. 

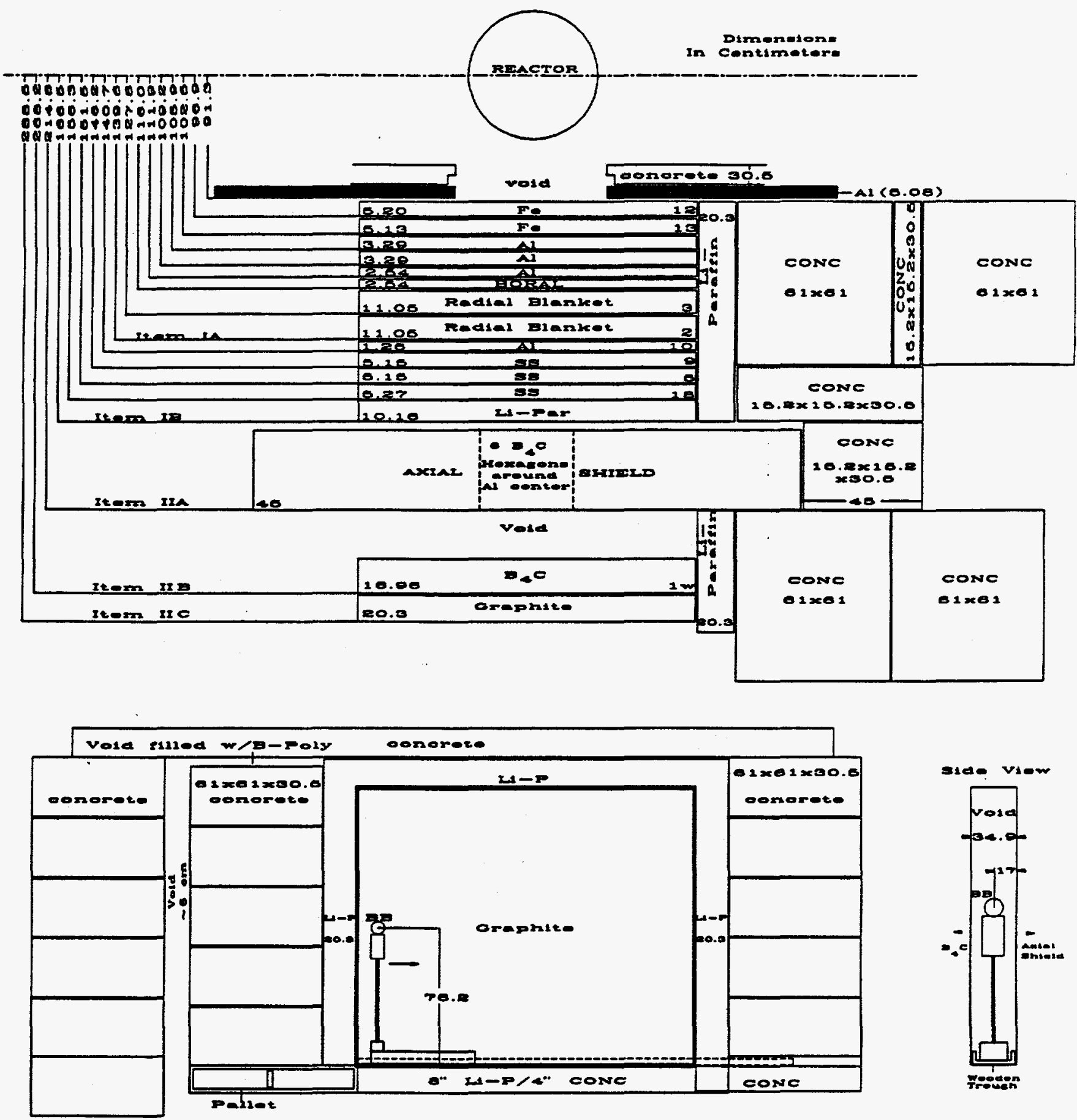

Figure 3. Schematic of SM plus shield configuration for Items IA, IB, IA, IIB, IIC. 
RADIAL BLANKET
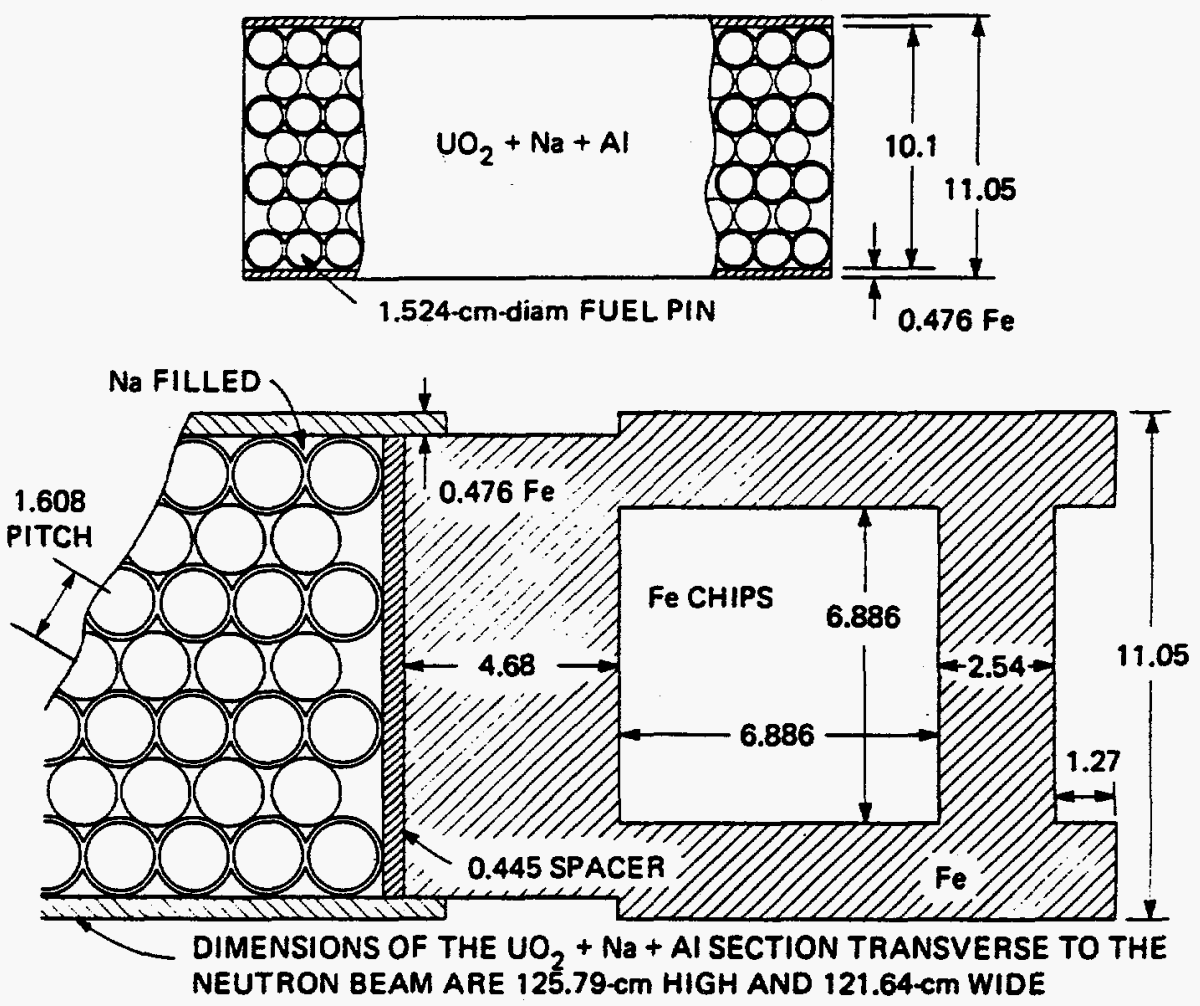

THEORETICAL DENSITY $=10.96 \mathrm{~g} / \mathrm{cc}$ ACTUAL DENSITY (0.94 THEO.) $=10.28 \mathrm{~g} / \mathrm{cc}$
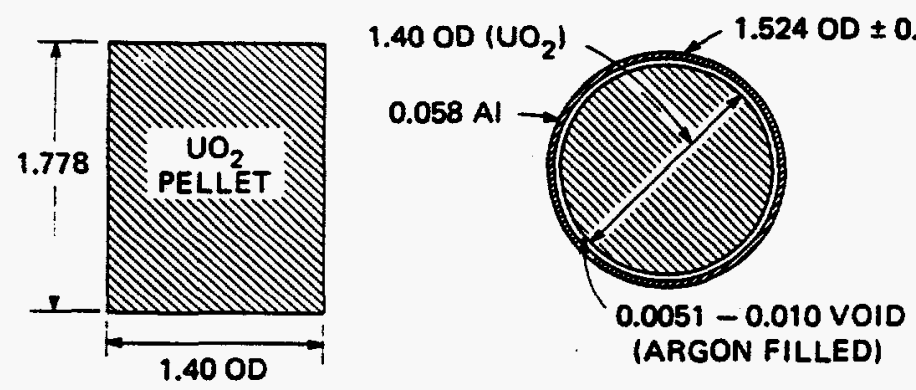

DIMENSIONS IN cm

Figure 4. Schematic of radial blanket slab containing $\mathrm{UO}_{2}$. 


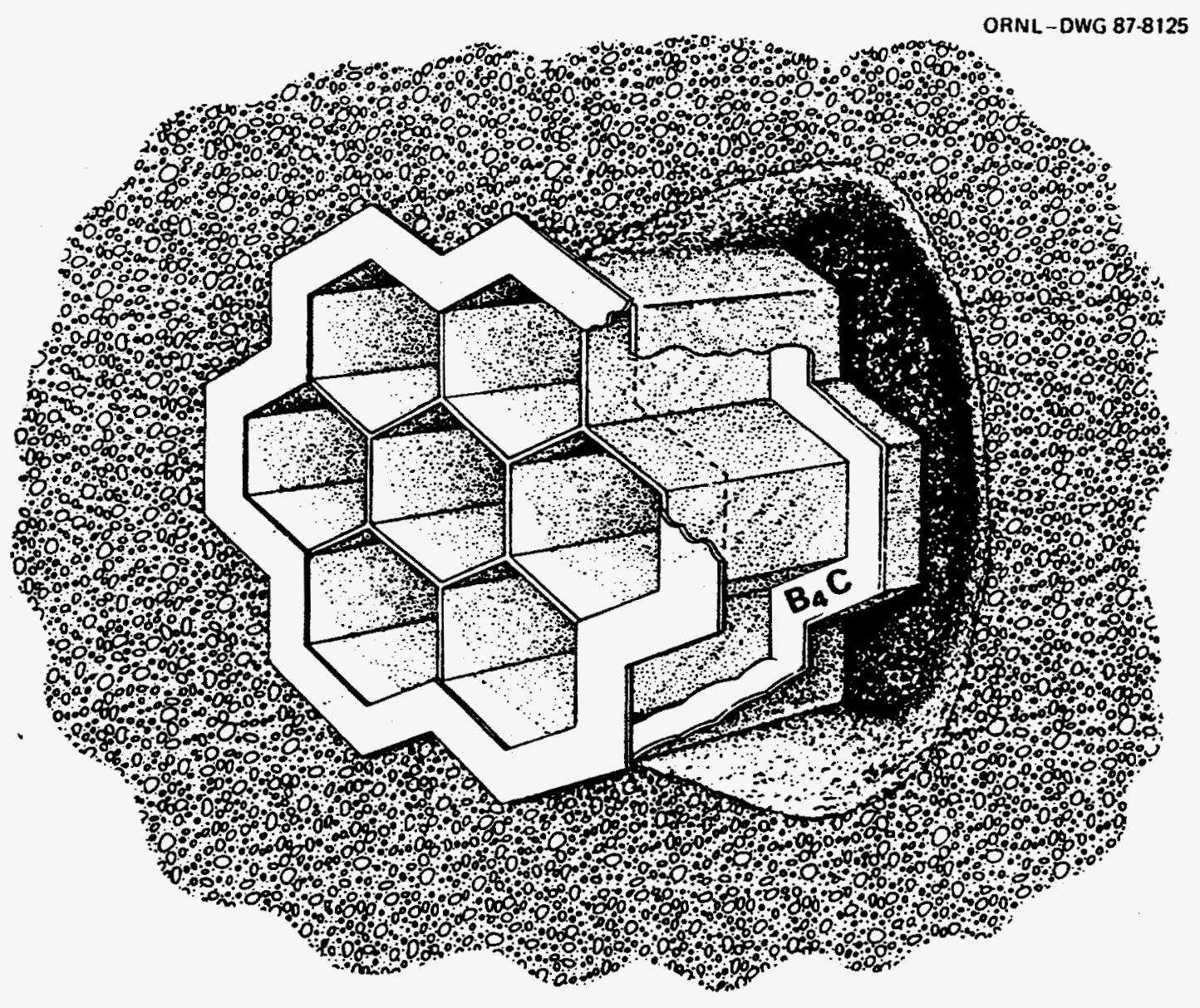

Figure 5. Schematic of the aluminum honeycomb within a concrete slab. 
ORNL.DWG 86-12606

\section{$B_{4}$ C CONTAINERS}

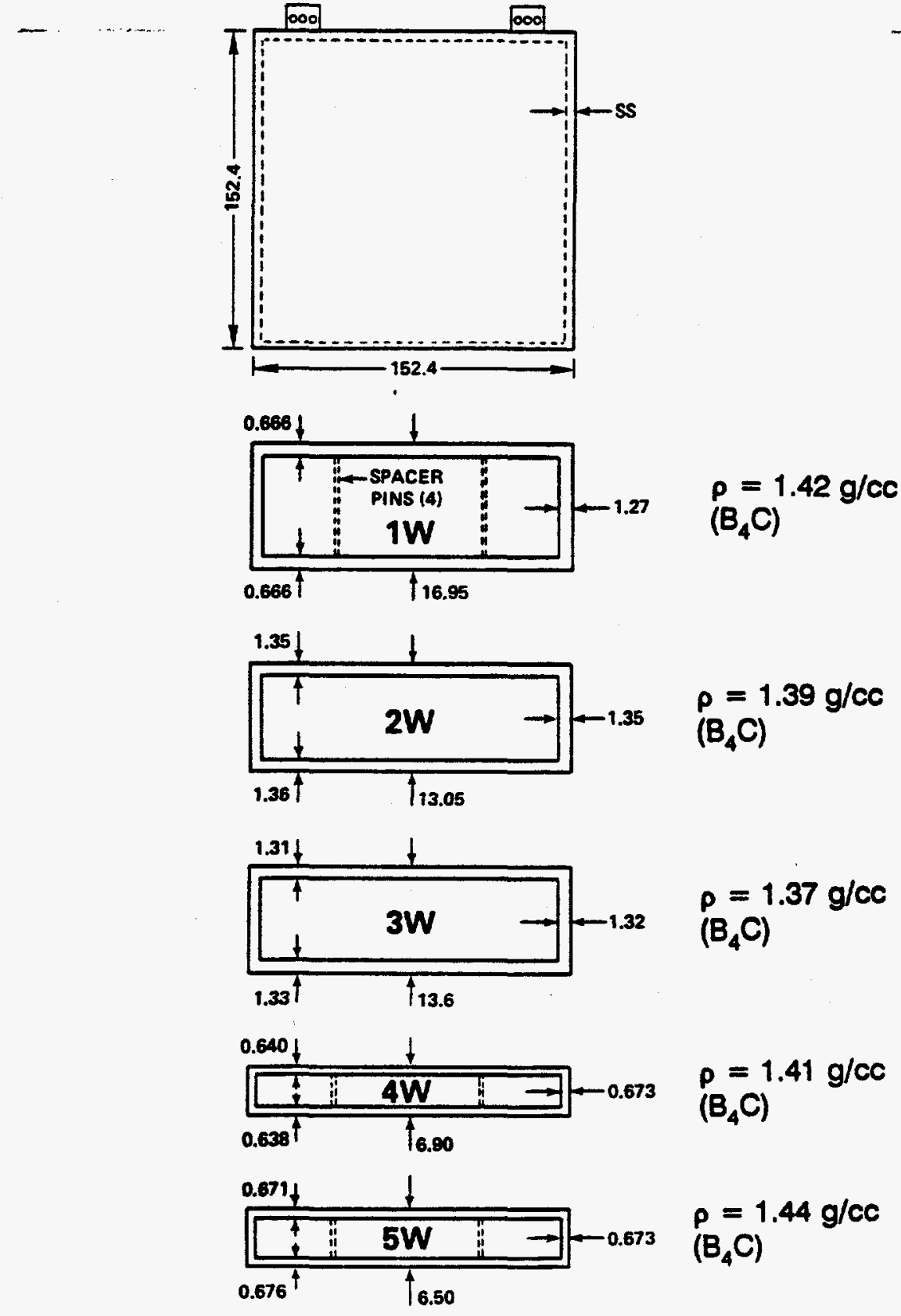

(ALL DIMENSIONS ARE IN CENTIMETERS)

Figure 6. Schematic of stainless steel containers used for boron carbide shield slabs. 


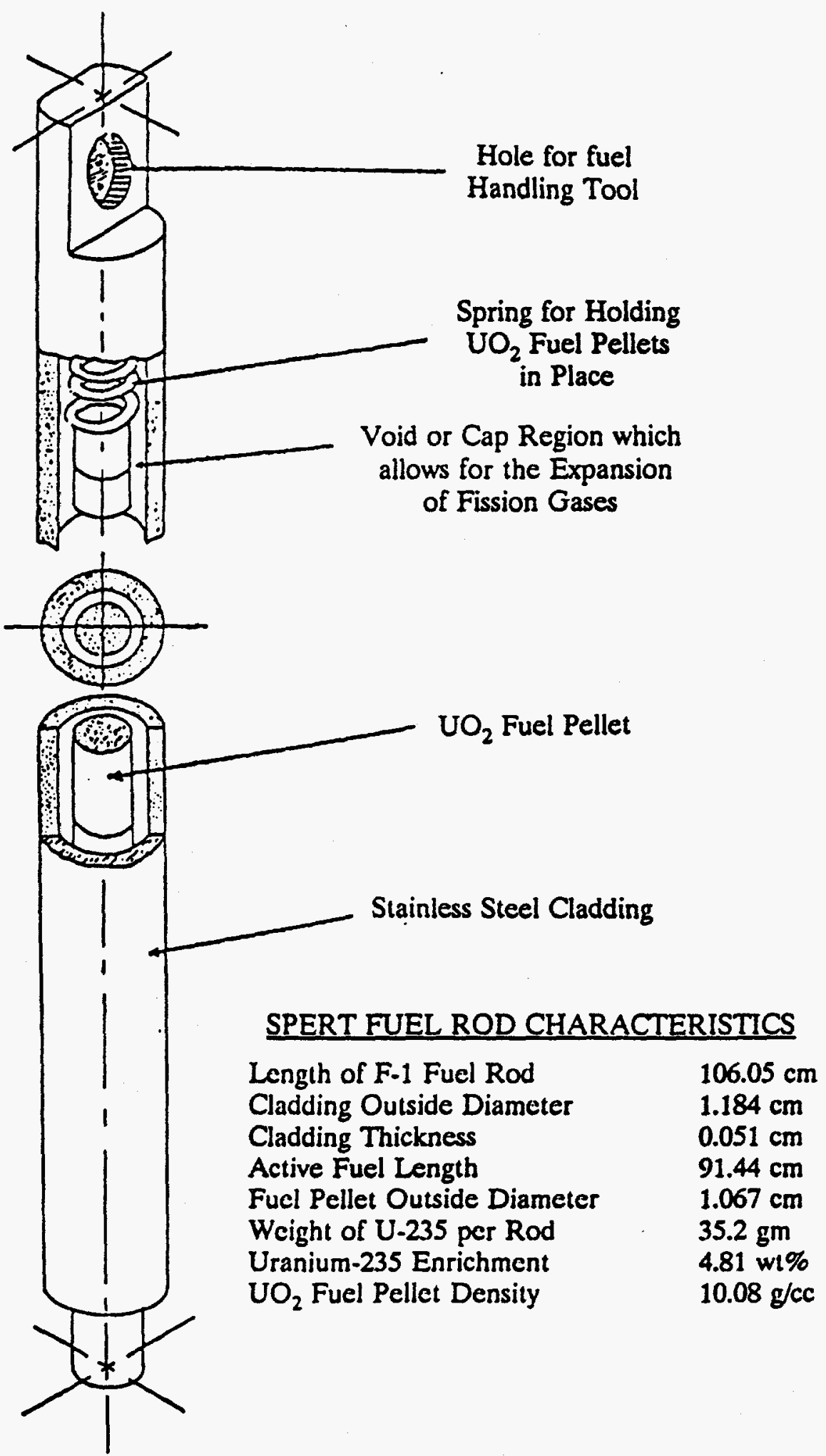

Figure 7. Isometric of the SPERT fuel rod containing Uranium-Dioxide fuel pellets. 

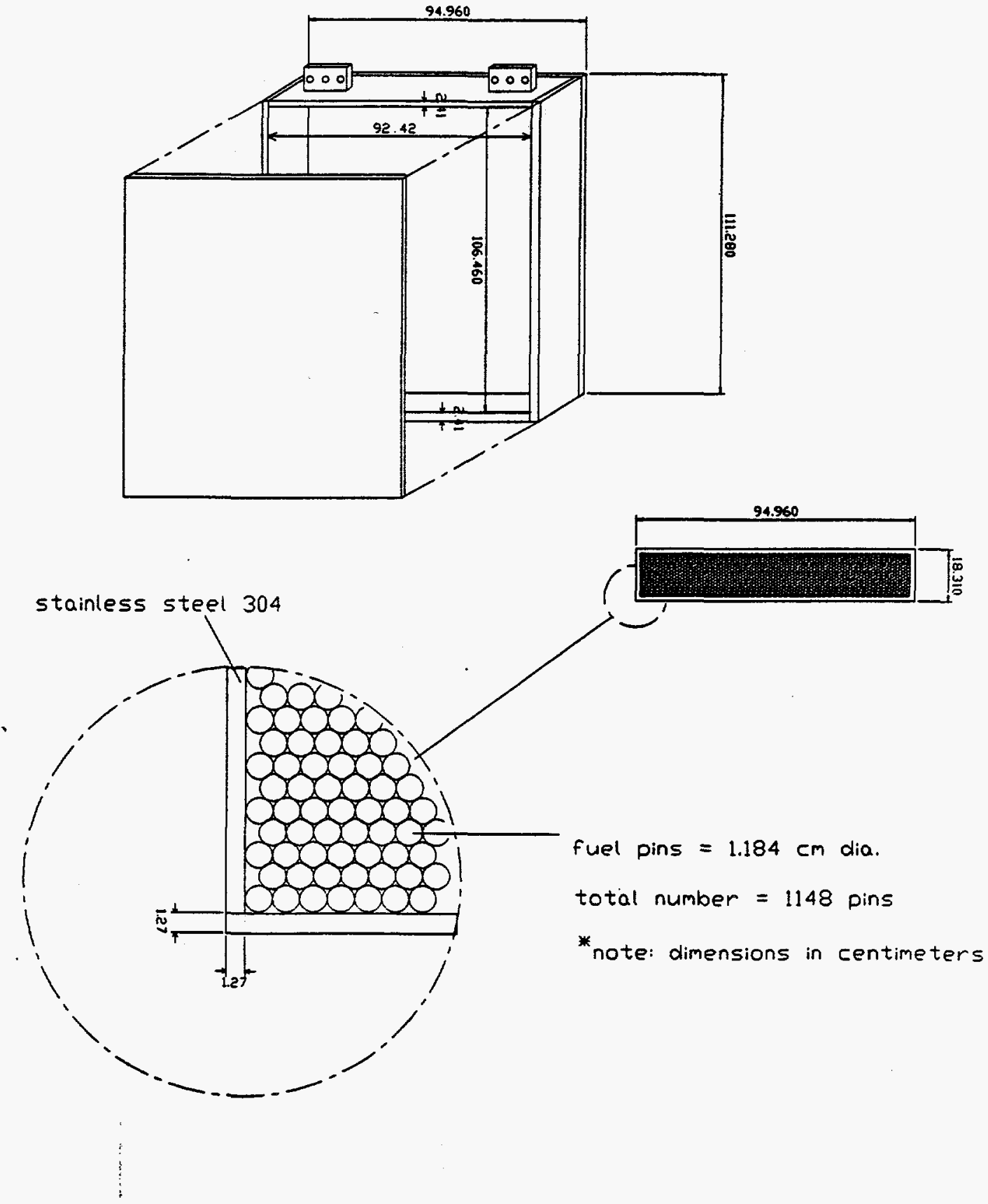

Figure 8. Schematic of thick IVFS mockup (slab \#1). 


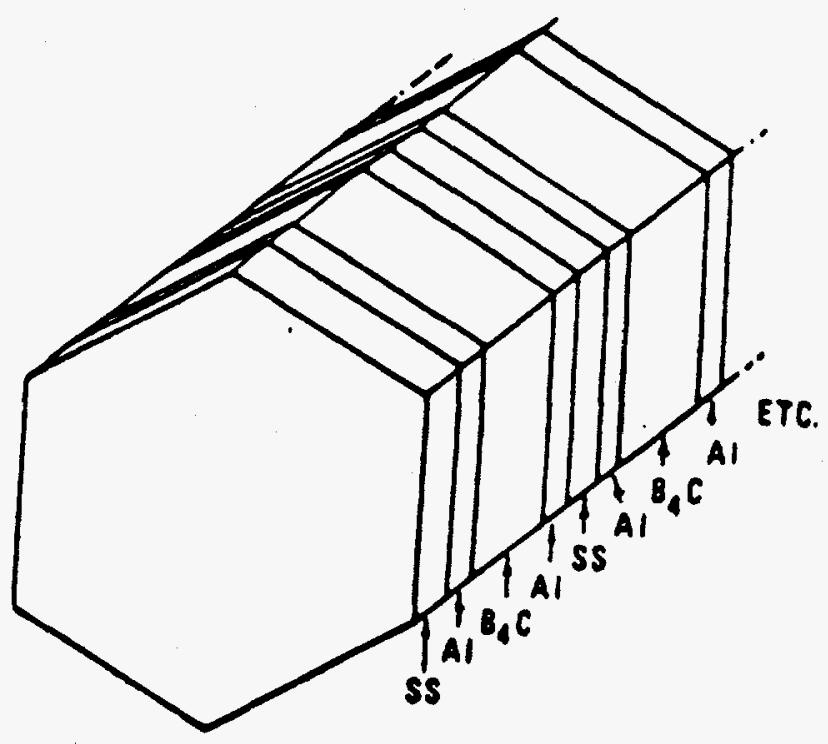

Depth of $\mathrm{B}_{4} \mathrm{C}$ in container: $7.77 \mathrm{~cm}$ ( 4 total) Width of $\mathrm{B}_{4} \mathrm{C}$ : $14.73 \mathrm{~cm}$

End plate thickness: $1.123 \mathrm{~cm}$

Wall thickness of container: $.627 \mathrm{~cm}$

Width of container (flat surface to flat surface: $15.98 \mathrm{~cm}$

Density of $\mathrm{B}_{4} \mathrm{C}: 1.41 \mathrm{~g} / \mathrm{cc}$

Thickness of SS pieces: $1.25 \mathrm{~cm}$ ( 4 total)

Figure 9. $\mathrm{B}_{4} \mathrm{C}$ homogeneous-type assembly. 


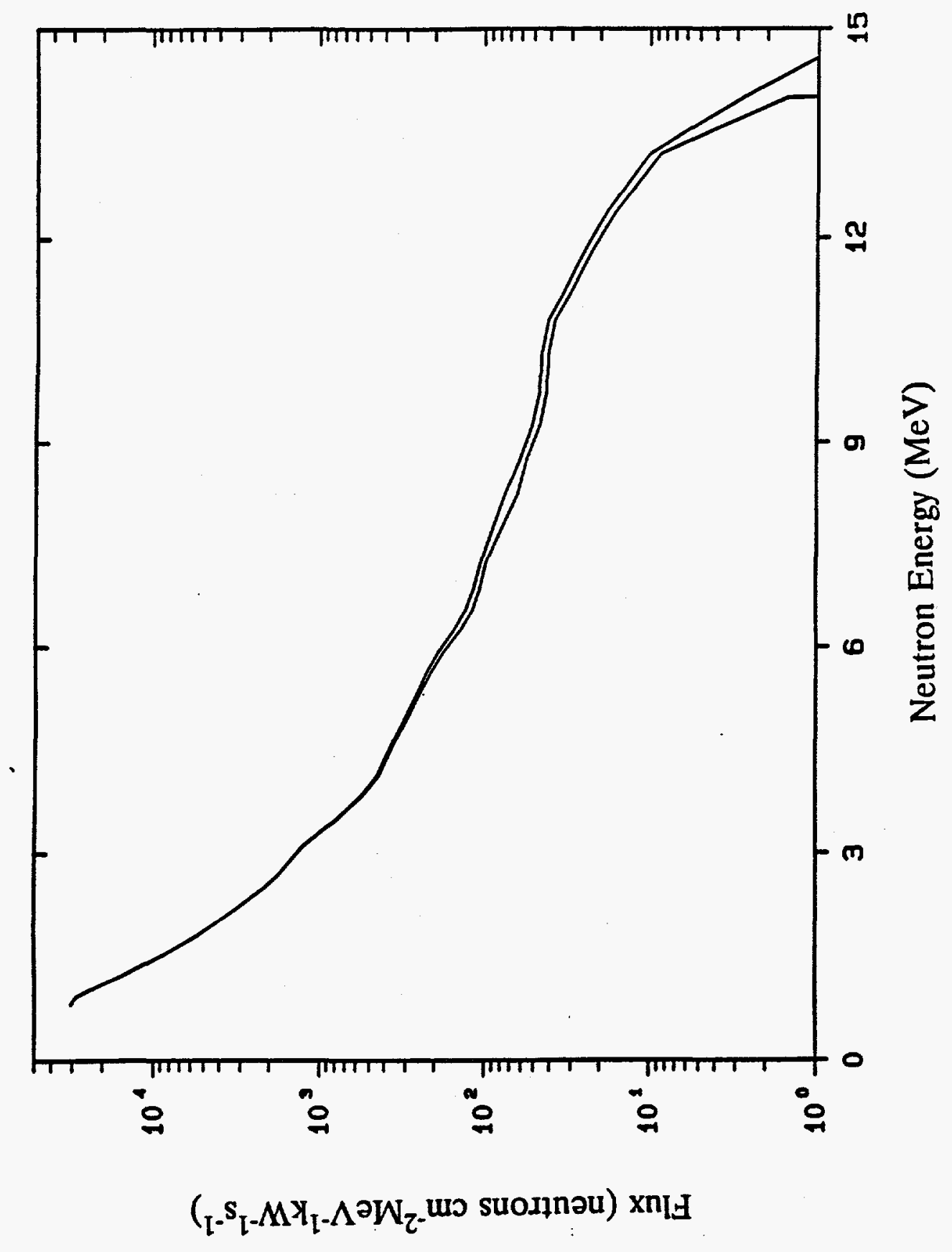

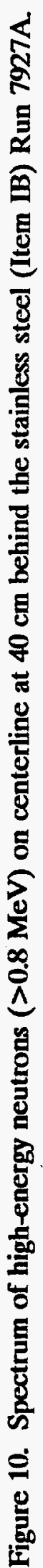




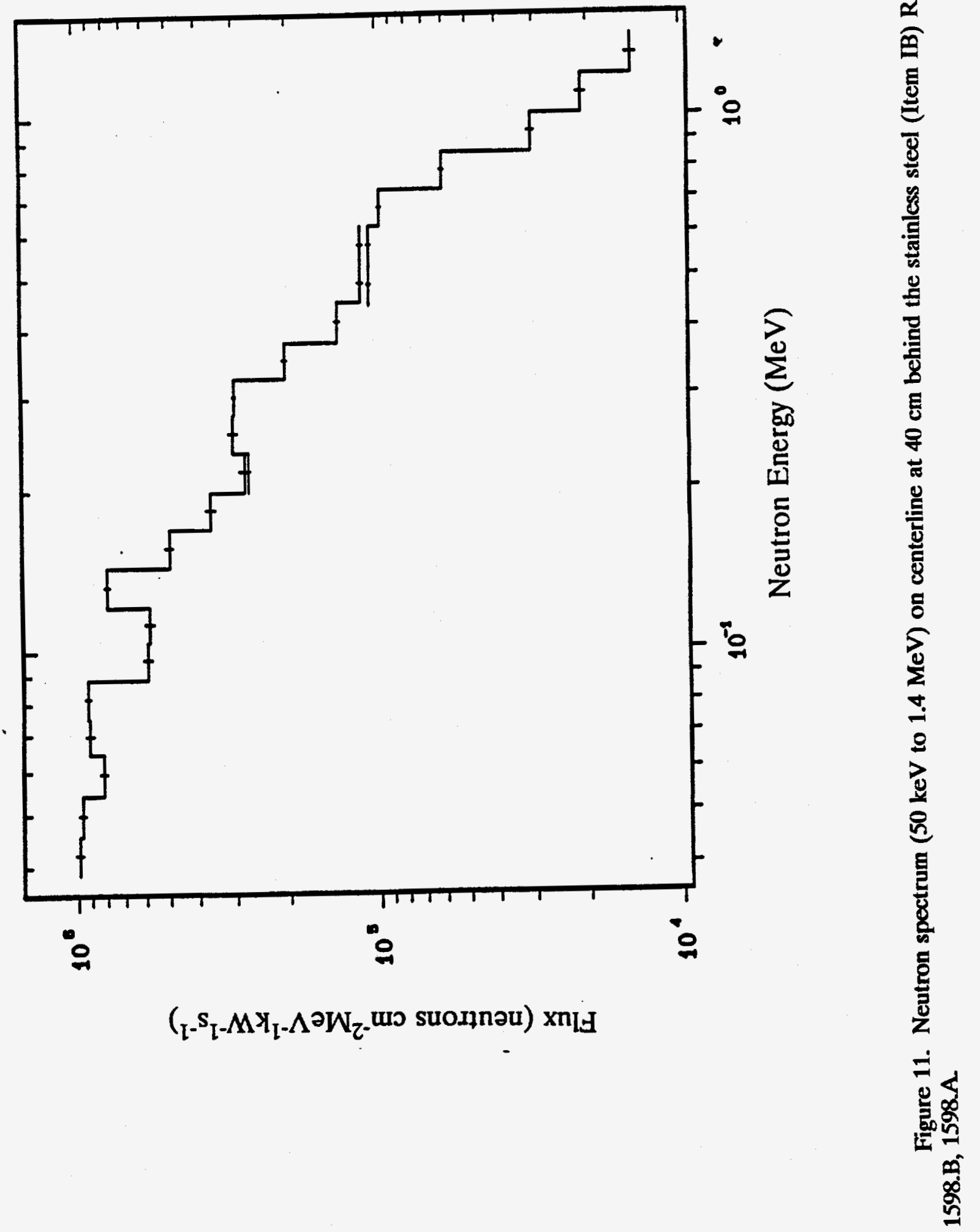




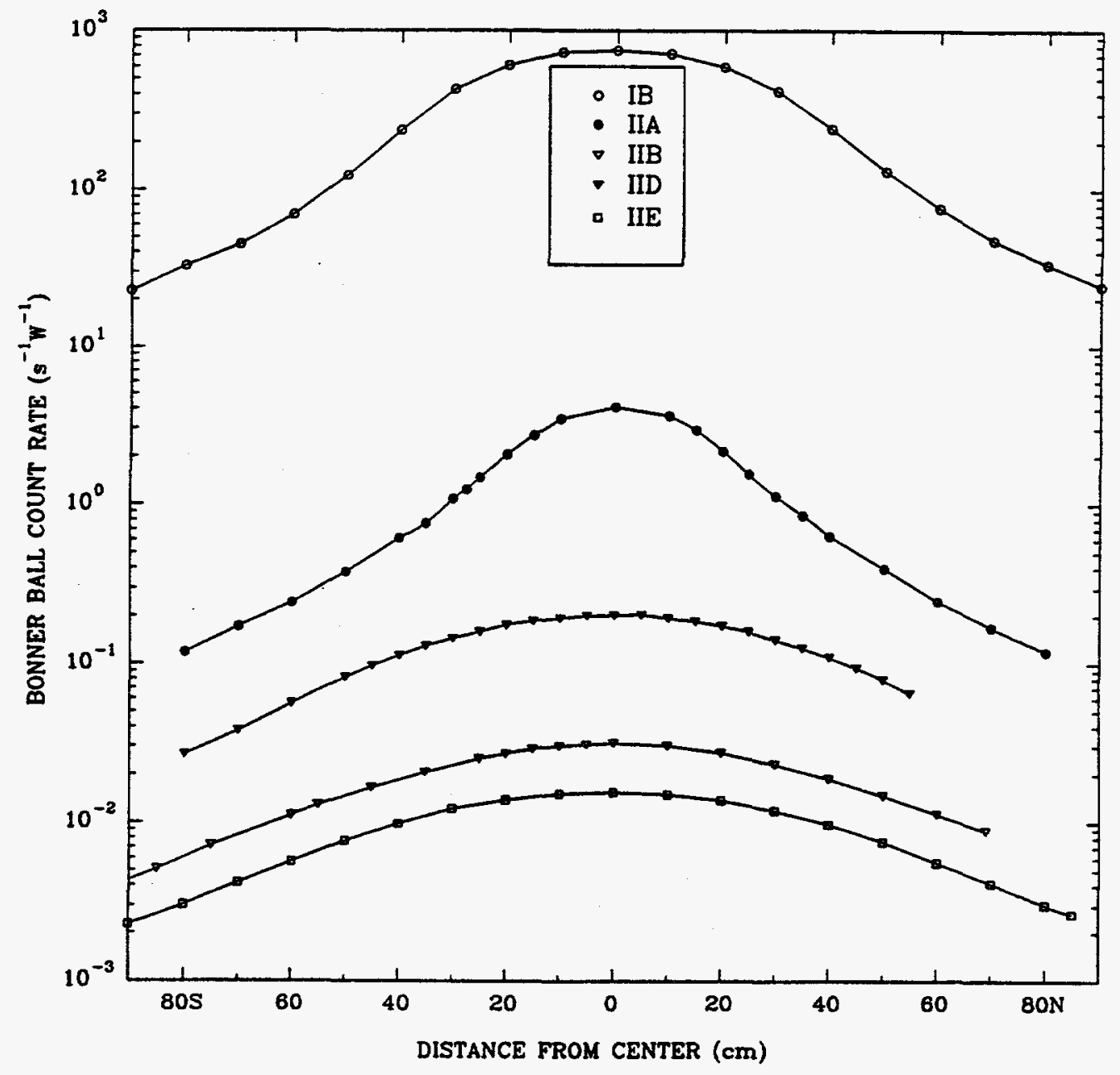

Figure 12 5-inch Bonner ball horizontal traverses through midplane at $30 \mathrm{~cm}$ behind the mockup. 


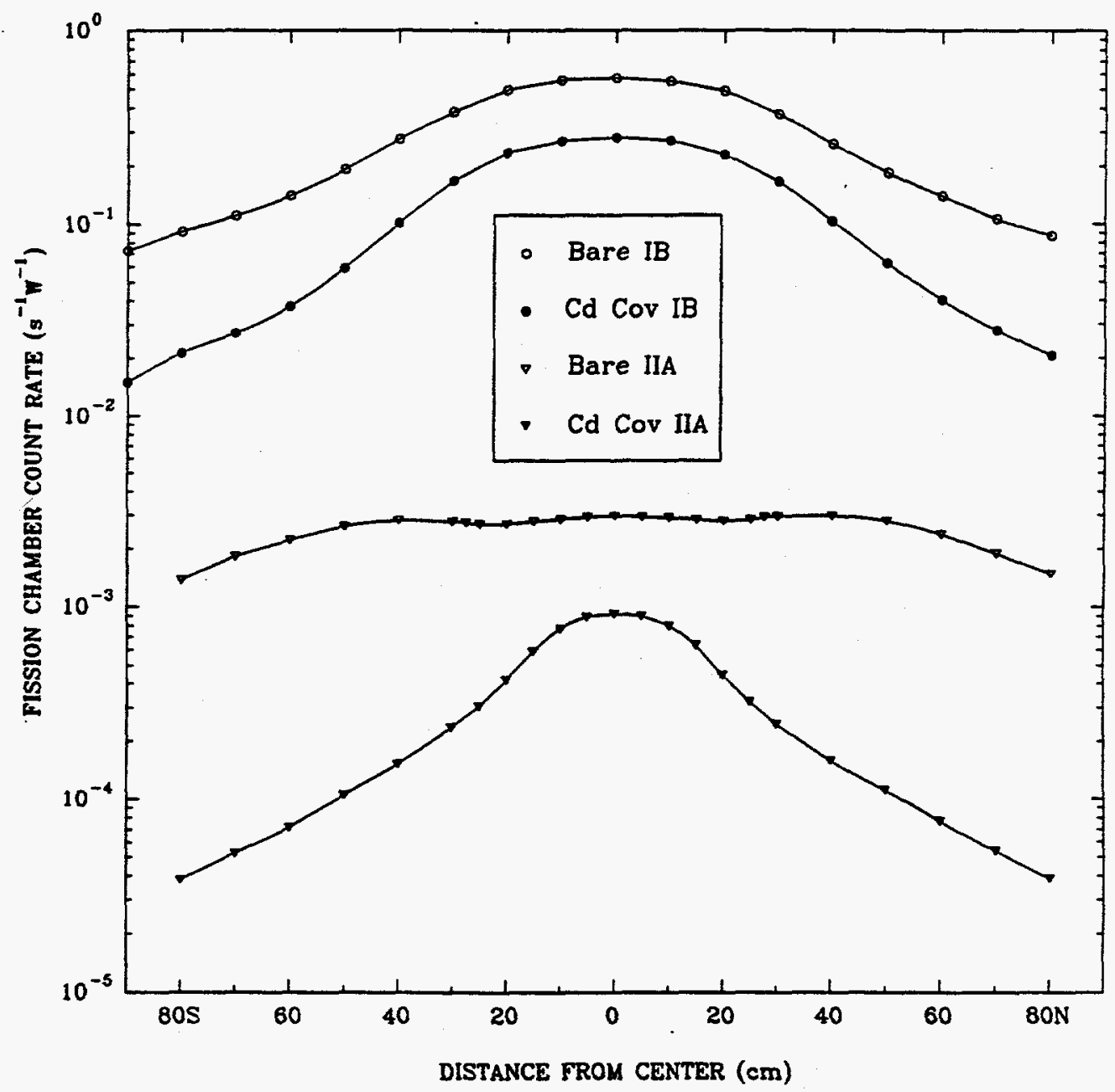

Figure 13. Bare and Cd-covered fission chamber horizontal traverses through midplane at $30 \mathrm{~cm}$ behind the mockup. 


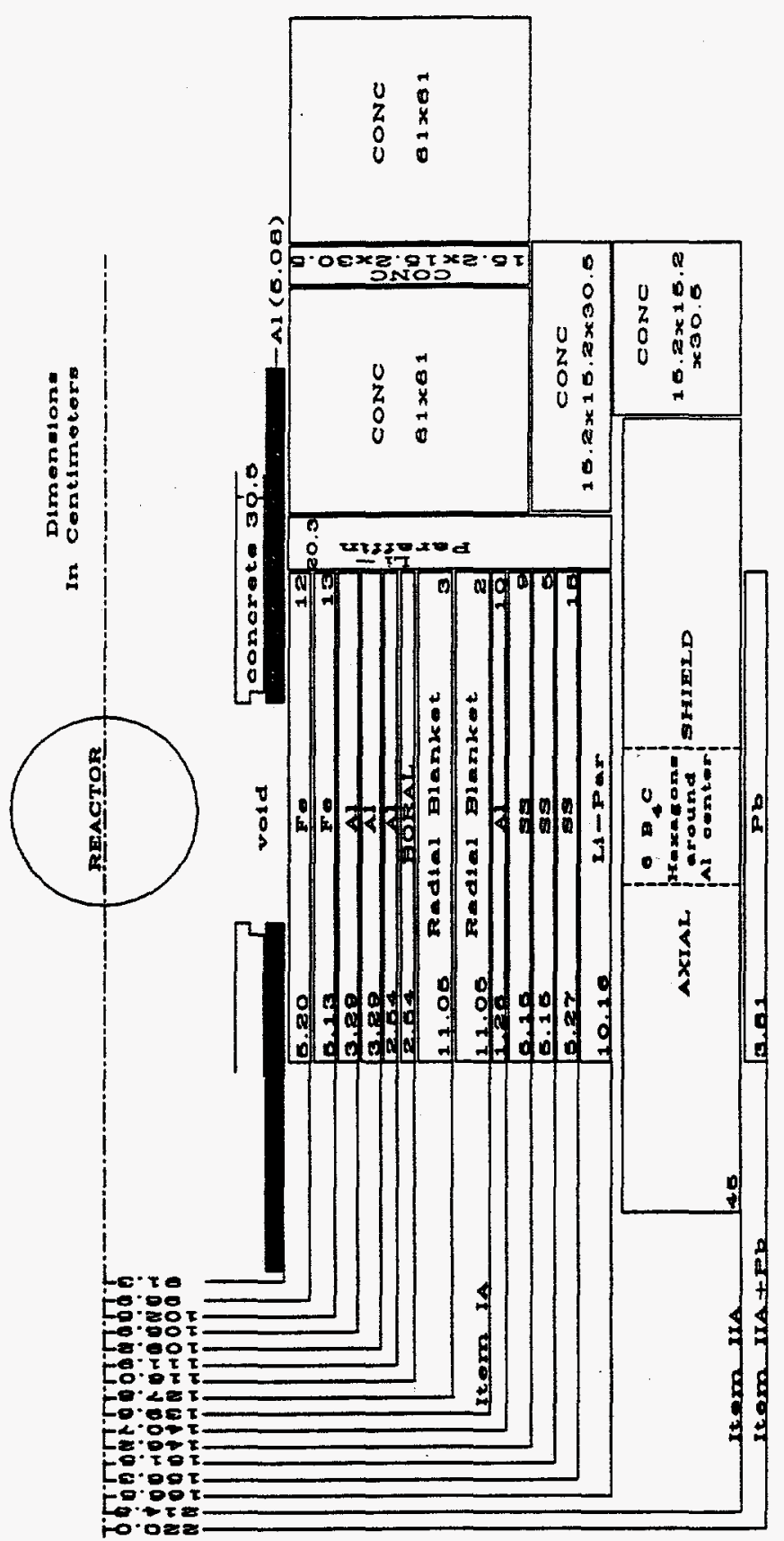

告 


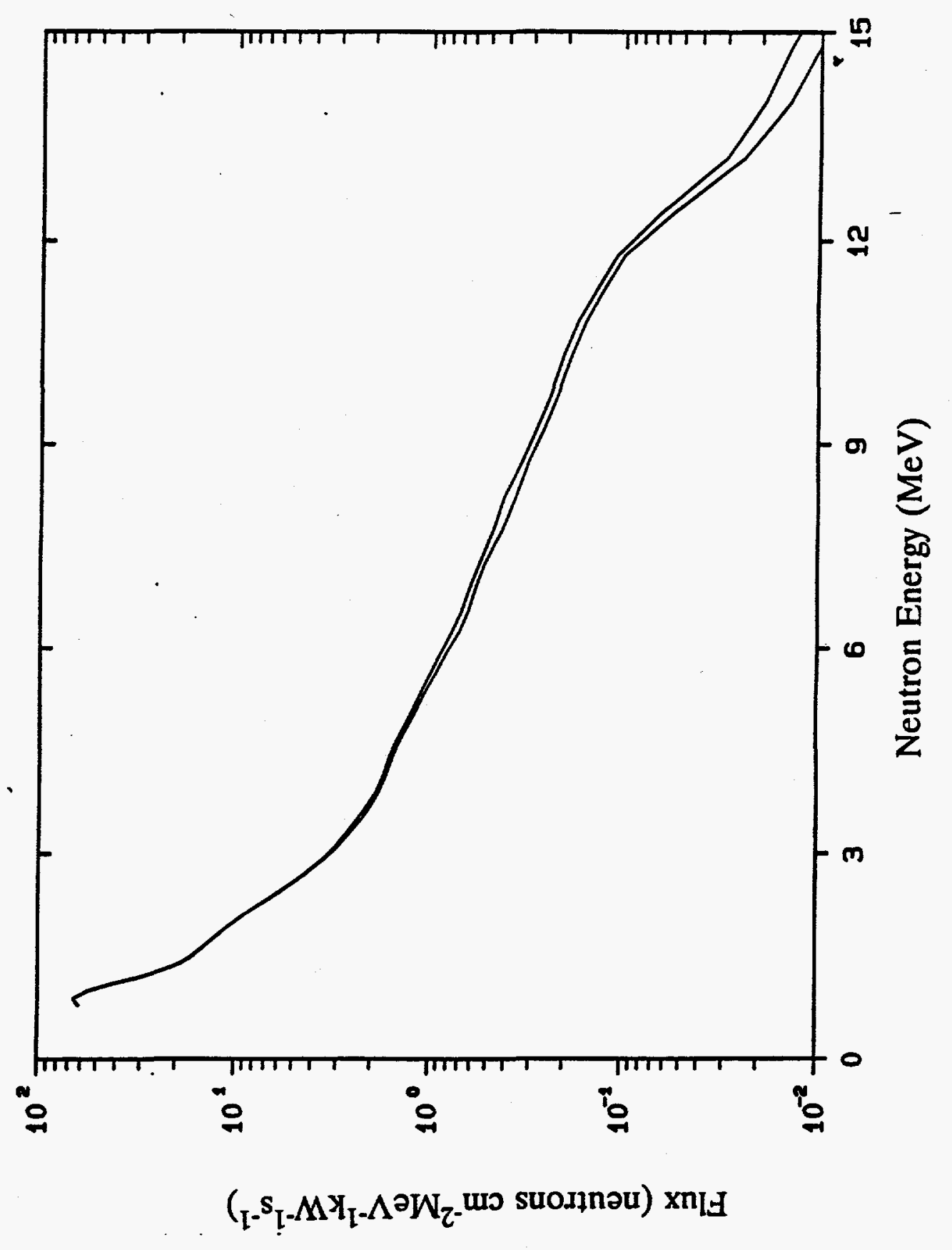

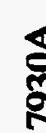




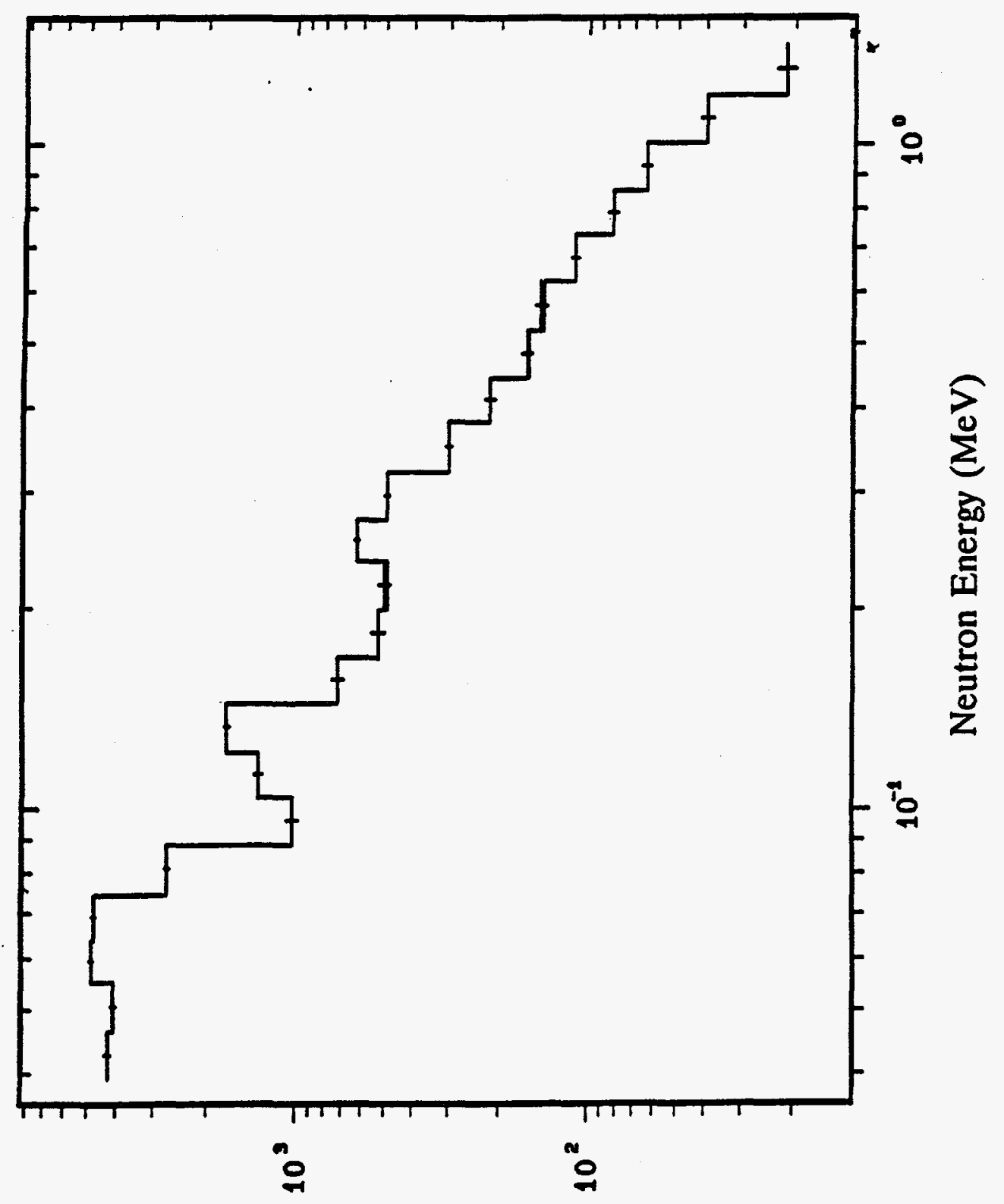

$\left({ }_{I}-s_{I}-M X_{I}-\Lambda^{\partial} W_{Z}-\right.$ wo suonnau $) x n_{I H}$ 


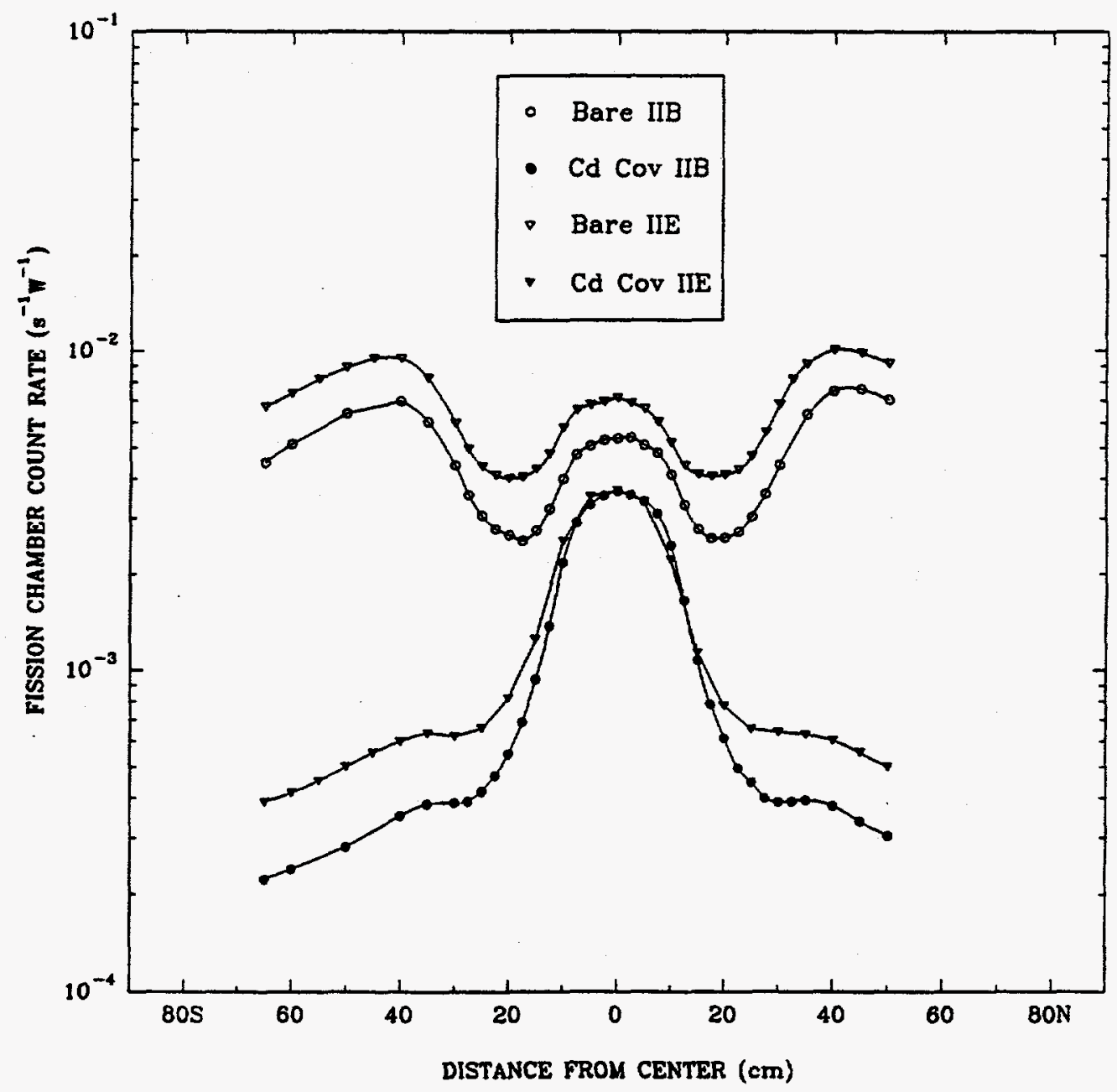

Figure 17. Bare and Cd-covered fission chamber horizontal traverses through midplane at $5 \mathrm{~cm}$ behind the axial shield in the void (Item IIB, IIE). 


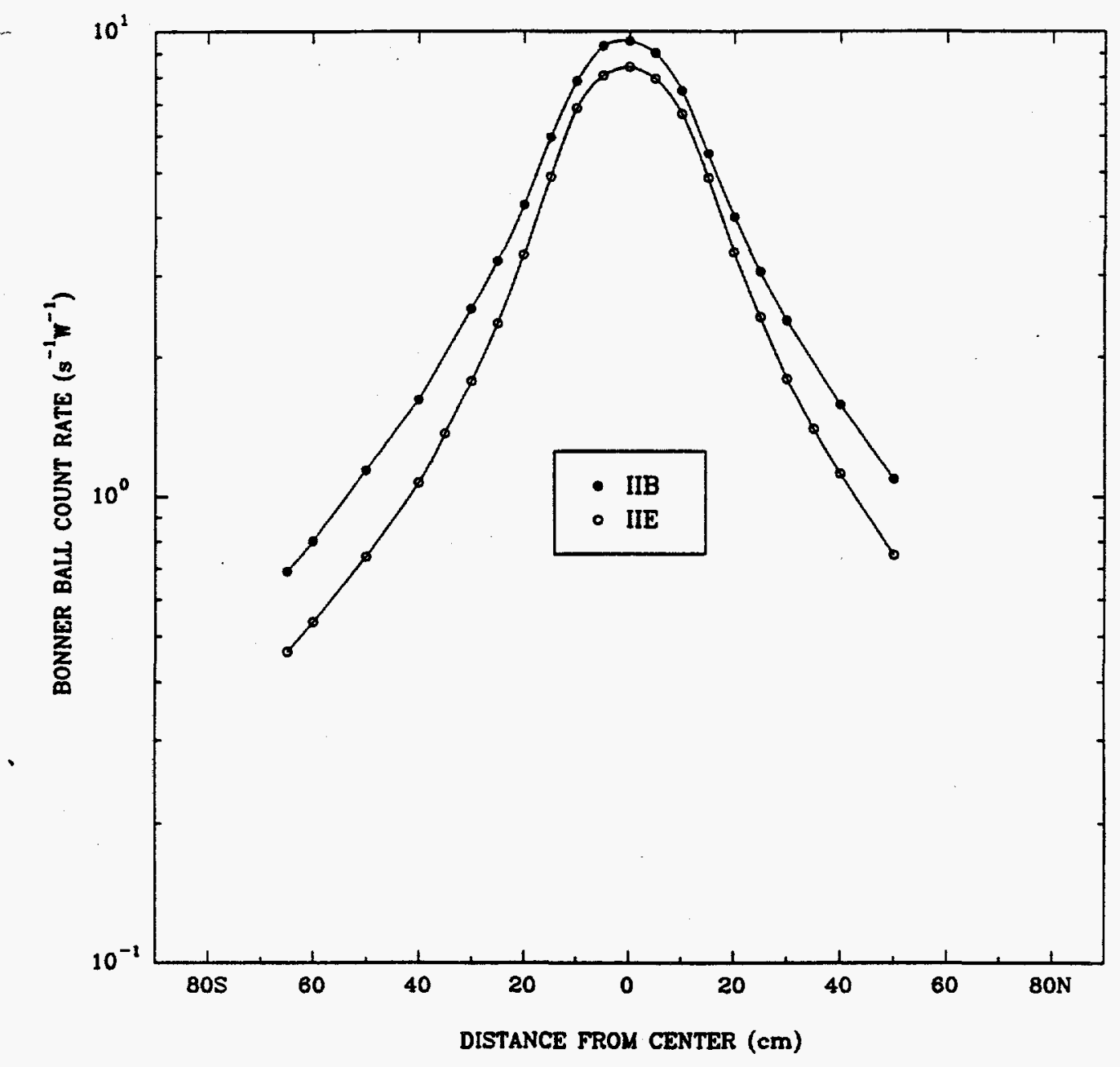

Figure 18. 5-inch Bonner ball horizontal traverses through midplane in the void behind the axial shield. 

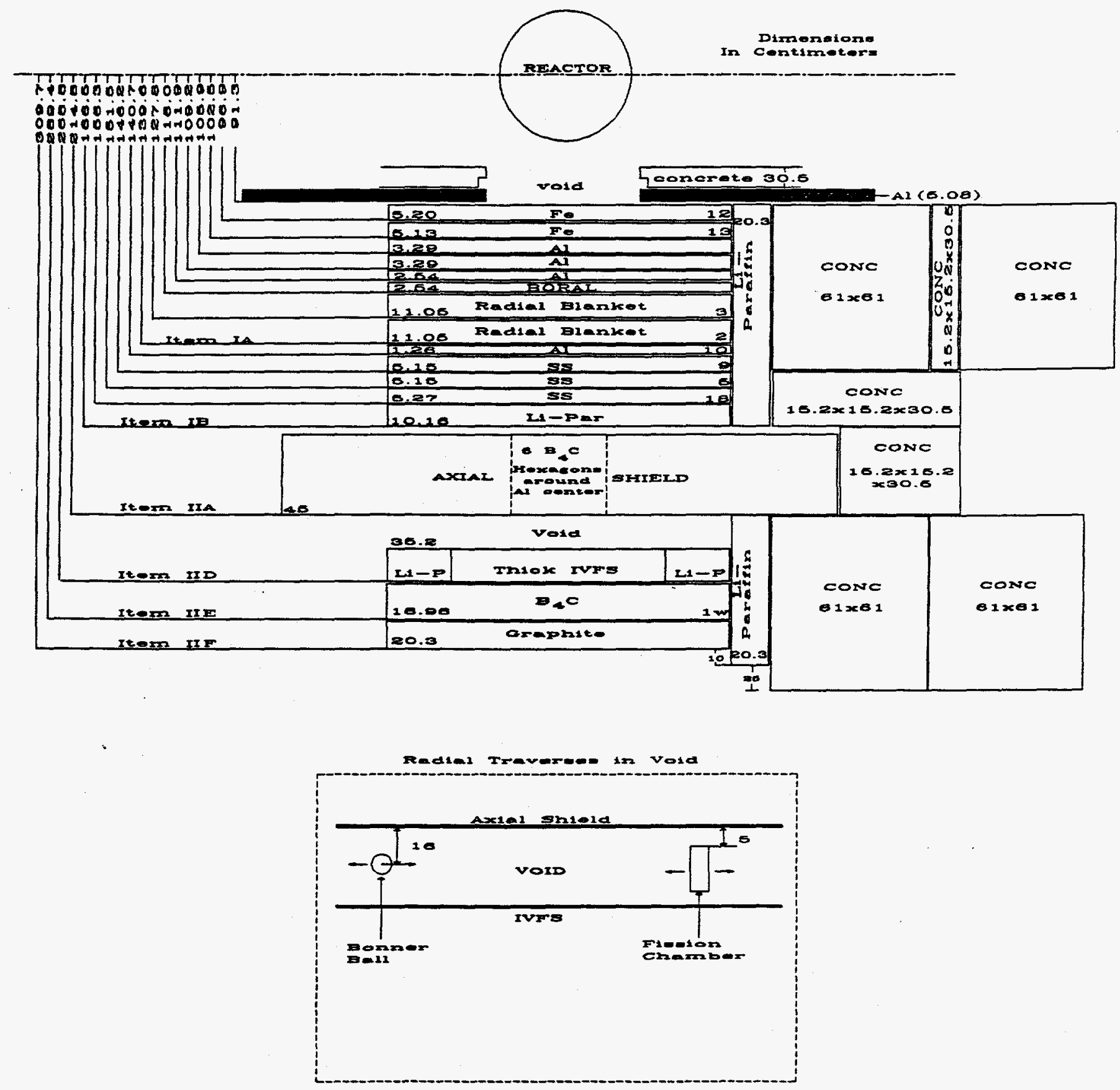

Figure 19. Schematic of SM plus shield configurations for Items IB, IIA, IID, IIE, IIF. 

ORNL/TM-12171

Distribution Category

UC-534'

\section{DISTRIBUTION}

1. B. R. Appleton

2. J. A. Bucholz

3. L. B. Holland

4. F. J. Homan

5. H. T. Hunter

6-15. D. T. Ingersoll

16-17. F. J. Muckenthaler

18. J. V. Pace, III

19. J. A. Ray

20. C. O. Slater
21. R. R. Spencer

22. R. C. Ward

23. J. D. White

24. A. Zucker

25. Central Research Library

26-30. EPMD Reports Office

31. ORNL Y-12 Technical Library

Document Reference Section

32-34. Laboratory Records

35. ORNL Patent Office

\section{EXTERNAL DISTRIBUTION}

36. Office of Assistant Manager for Energy Research and Development, DOE-OR, P.O. Box 2008, Oak Ridge, TN 37831-6269.

37. L. F. Blankner, Energy Research and Development, DOE-OR, P.O. Box 2008, Oak Ridge, TN 37831-6269.

38. Prof. Roger W. Brockett, Harvard University, Pierce Hall, 29 Oxford Street, Cambridge, Massachusetts 02138.

39. L. L. Carter, Westinghouse-Hanford Company, 400 Area Trailer 1, P.O. Box 1970, Richland WA 99352.

40. R. K. Disney, Westinghouse Electric Company, P.O. Box 158, Madison, PA 15663.

41. Prof. John J. Dorning, Department of Nuclear Engineering and Engineering Physics Reactor Facility, University of Virginia, Charlottesville, VA 22903.

42. P. B. Hemmig, Safety and Physics Branch, Office of Technology Support Programs, DOE-Washington, Washington, DC 20585.

43. Dr. James E. Leiss, Route 2, Box 142C, Broadway, VA 22815.

44. Prof. Neville Moray, Department of Mechanical and Industrial Engineering, 1206 West Green Street, Urbana, IL 61801. 
45. Prof. Mary F. Wheeler, Department of Mathematical Sciences, Rice University, P.O. Box 1892, Houston, TX 77251.

46. K. Itoh, Power Reactor and Nuclear Fuel Development Corporation, Sankaido Building, 9-13, 1-Chome, Akasaka, Minato-Ku, Tokyo 107, Japan.

47. A. Shono, Oarai Engineering Center, Power Reactor and Nuclear Fuel Development Corporation, 4002, Marita, Oarai-Machi, Higashi-Kbaraki-Gun, Ibaraki-Ken, 311-13, Japan.

48. M. Tsutsumi, Power Reactor and Nuclear Fuel Development CorporationWashington, Suite 715, 2600 Virginia Avenue NW, Washington, DC 20037.

49. K. Chatani, Power Reactor and Nuclear Fuel Development Corporation, 4002 Narita-Cho, O-Arai-Machi, Ibaraki-Ken, 311-13, Japan.

50-122. Given distribution as shown in DOE/OSTI-4500-R75, LMFBR-Physics: 